\title{
ELETROCOAGULAÇÃO/ELETROFLOCULAÇÃO PARA TRATAMENTO DE ÁGUAS RESIDUÁRIAS: ELETRODOS NÃO CONVENCIONAIS E ACOPLAMENTO DE TÉCNICAS
}

\author{
Luís Henrique Araújo Greccoa,*, (), Bárbara Camila de Araújo Souza e Maria Valnice Boldrin Zanoni ${ }^{\mathrm{a}}$ \\ aDepartamento de Química Analítica, Físico-Química e Inorgânica, Instituto de Química, Universidade Estadual Paulista "Júlio \\ de Mesquita Filho", 14800-900 Araraquara - SP, Brasil
}

Recebido em 28/06/2021; aceito em 20/10/2021; publicado na web em 30/11/2021

\begin{abstract}
ELECTROCOAGULATION/ELECTROFLOCULATION FOR WASTEWATER TREATMENT: NON-CONVENTIONAL ELECTRODES AND COUPLING OF TECHNIQUES. Electrocoagulation-electroflotation (EC) technology is a well-known wastewater treatment process that consists of applying electric current to remove contaminants without requiring the addition of chemicals that can generate secondary pollutants. Once they are the most widely used, iron and aluminum electrodes are considered conventional, however they leave unwanted residues, which will give a yellowish-brown color to the treated water, in the case of iron electrodes, and are associated with potential risks to human health, in the case of aluminum electrodes. In this regard, the study of non-conventional electrodes capable of circumventing those problems is essential for the development of more effective wastewater treatments. In this review article, a brief presentation will be made of the history of electrofloculation followed by a brief discussion of conventional electrodes and the mechanisms that govern the processes of removing contaminants by the electrocoagulation process. Subsequently, the non-conventional electrodes reported in the literature up to the present moment will be presented, as well as their potential, applications and performance when applied in water treatment. Finally, will be discussed the coupling of the electroflotation with other water treatment techniques towards achieving a better-quality reuse water.
\end{abstract}

Keywords: nickel electrodes; advanced oxidative process; titanium electrodes; zinc electrodes; steel electrodes; electrochemistry.

\section{INTRODUÇÃO}

A eletrofloculação consiste em um método eletroquímico para o tratamento de água que associa dois fenômenos eletroquímicos: a eletrocoagulação e a eletroflotação. ${ }^{1} \mathrm{Um}$ dos registros pioneiros do uso desta técnica foi o trabalho de J. T. Harries no ano de 1909. Nesse trabalho, o autor destaca o uso de ferro e alumínio, como ânodos de sacrifício, para formação de hidróxido de ferro e hidróxido de alumínio, bem como para a formação de bolhas de gás hidrogênio, capazes de promover a coagulação e flotação de materiais suspensos e coloidais. ${ }^{2}$ No entanto, o uso da técnica eletroquímica para geração do coagulante e correspondente floculação só foi aplicada em larga escala para tratamento de água potável a partir de $1946 .{ }^{3} \mathrm{E}$ a partir de 1980 a eletrofloculação ganhou destaques para tratamento de águas contaminadas, principalmente emulsões óleo/água. ${ }^{4}$ Atualmente configura-se em uma técnica bastante popular para tratamento de águas residuárias tanto em pequenas quanto largas escalas. ${ }^{5-7}$ Ademais, é interessante ressaltar que esta técnica, por conta de sua simplicidade experimental, se mostra como uma alternativa interessante para a realização de práticas laboratoriais para estudantes, de forma que vários conceitos sobre eletroquímica e tratamento de água podem ser abordados, como mostrado no trabalho de Neto et al. ${ }^{8}$

A eletrocoagulação é um método derivado da coagulação química, sendo esta conhecida previamente como técnica de tratamento de água, a qual se baseia na adição de compostos coagulantes na solução a ser tratada, tais como: sulfato de alumínio, cloreto de alumínio, cloreto férrico e sulfato férrico. ${ }^{9}$ Esses compostos, adicionados em quantidades suficientes em um meio com $\mathrm{pH}$ adequado, podem promover a formação de compostos pouco solúveis capazes de remover pequenas partículas suspensas pela adsorção e formação de aglomerados, os quais podem ser removidos mais facilmente da água, após o processo de coagulação. As maiores desvantagens

*e-mail: grecco421@gmail.com do método estão relacionadas a necessidade da adição constante de uma quantidade significativa de reagentes, rigoroso controle de $\mathrm{pH}$, elevado custo operacional e geração de grande quantidade de resíduos. Esses resíduos, por sua vez, podem apresentar riscos toxicológicos, e devem ser dispostos em aterros específicos segundo a Política Nacional de Resíduos Sólidos. ${ }^{10}$ Como consequência, podem ocasionar poluição secundária cumulativa. ${ }^{7}$

A eletroflotação, por outro lado, consiste na separação de materiais suspensos (sólidos ou líquidos) de uma solução aquosa por meio da agregação desses poluentes às bolhas de gás hidrogênio produzidas no cátodo pela reação de hidrólise da água. ${ }^{11}$ Uma vez formados, esses agregados se dirigirem à superfície da solução, permitindo a sua separação do meio e, consequentemente, a remoção desses materiais da solução. ${ }^{12}$ Uma aplicação interessante da eletroflotação no tratamento de água é o trabalho dos pesquisadores Paschoal e Tremiliosi-Filho, que demonstraram a potencialidade da técnica de eletrofloculação com eletrodo de $\beta-\mathrm{PbO}_{2}$ para a recuperação do corante índigo blue, presente em efluentes gerados na manufatura do jeans. ${ }^{13}$

A técnica de eletrocoagulação tem se mostrado uma alternativa viável à coagulação química, e emprega corrente elétrica para a geração de coagulantes químicos in situ, que se formam por meio de reações de oxidação eletrolítica de um material apropriado, usado como ânodo de sacrifício. No cátodo, há a simultânea formação de bolhas de gás hidrogênio, ${ }^{14}$ propiciando o processo de eletrofloculação do precipitado. Essas etapas são resumidas pelas reações 1-3:

Ânodo:

$$
\mathrm{M}_{(\mathrm{s})}^{0} \rightarrow \mathrm{M}_{(\mathrm{aq})}^{\mathrm{n}+}+\mathrm{ne}^{-}
$$

Em solução:

$$
\mathrm{M}_{(\mathrm{aq})}^{\mathrm{n}+}+\mathrm{nOH}_{(\mathrm{aq})}^{-} \rightarrow \mathrm{M}(\mathrm{OH})_{\mathrm{n}(\mathrm{s})}
$$

Cátodo:

$$
2 \mathrm{H}_{2} \mathrm{O}_{(1)}+2 \mathrm{e}^{-} \rightarrow 2 \mathrm{OH}_{(\mathrm{aq})}^{-}+\mathrm{H}_{2(\mathrm{~g})}
$$


A partir de reações eletroquímicas fundamentais (Equações $1 \mathrm{e}$ 3), uma série de fenômenos físico-químicos e de reações químicas complexas ocorrem simultaneamente, como por exemplo: hidrólise dos íons gerados, ${ }^{14}$ neutralização da carga de particulados dispersos, ${ }^{15}$ complexação e adsorção de compostos orgânicos, ${ }^{16}$ formação de agentes coagulantes ${ }^{14}$ (Equação 2) e formação de átomos livres de oxigênio que, na presença de compostos orgânicos em solução, promovem reações de oxidação. ${ }^{17}$ É necessário pontuar que, no mesmo reator eletroquímico, há a geração de hidrogênio na forma gasosa (Equação 3), que, pela formação de agregados gás-coágulo, levam o contaminante para a superfície por eletrofloculação, sendo assim facilmente separados da água. ${ }^{14}$

A técnica de eletrocoagulação/eletrofloculação tem ganhado destaque no tratamento de água pela alta portabilidade, fácil operacionalidade, baixo custo, fácil manutenção dos equipamentos, eficiência em matrizes diversas e não necessidade de adição externa constante de produtos químicos. ${ }^{15,18}$ A literatura documenta vários trabalhos descrevendo os princípios básicos e aplicação da técnica para tratamento de água. ${ }^{14,15}$

Uma representação do processo de eletrocoagulação é mostrada a seguir (Figura 1). Nela, pode-se observar: (A) uma fonte de energia conectada a dois eletrodos imersos em uma solução vermelha dentro de um reator cilíndrico, representando o sistema antes do tratamento e (B) o mesmo sistema após o tratamento, no qual a solução tratada apresenta uma coloração azul, o ânodo apresenta uma coloração roxa, indicando a possível formação de uma camada passivante, além de apresentar irregularidades, indicando a ocorrência da corrosão. Ademais, em (B) há uma série de esferas vermelhas no fundo do reator, representando o agente coagulante que, ao ser formado durante o processo, retirou os poluentes do meio.

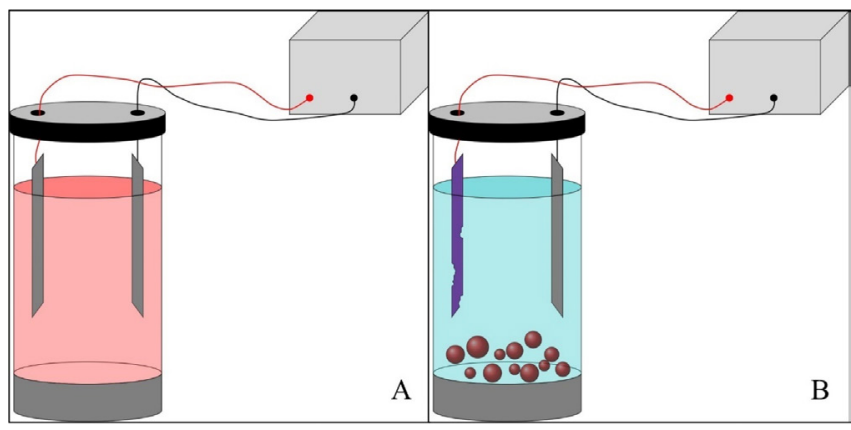

Figura 1. Representação dos sistemas eletroquímicos para tratamento de água antes do processo de eletrocoagulação $(A)$ e depois do processo (B)

O material eletródico é, sem dúvida, a parte mais importante em um processo de eletrocoagulação/eletrofloculação. ${ }^{3}$ Dentre eles, o Ferro e Alumínio ainda são os eletrodos com maiores aplicações em tratamento de água. Apesar destes eletrodos oferecerem alta eficiência de coagulação, ambos mostram baixo sobrepotencial de polarização ${ }^{19} \mathrm{e}$ alta solubilidade, ${ }^{20}$ interferindo significativamente na sua durabilidade. Além disso, embora as reações envolvendo o uso destes materiais sejam muito bem conhecidas, também é reportado que podem produzir resíduos indesejados. No caso do eletrodo de ferro, a solução ao final do tratamento pode apresentar uma coloração amarelada devido à formação de finos particulados compostos por óxidos de ferro ${ }^{21,22}$ e/ou desenvolvimento de ferrobactérias responsáveis pela oxidação de $\mathrm{Fe}(\mathrm{II})$ a $\mathrm{Fe}(\mathrm{III}) .{ }^{23,24}$ No caso dos eletrodos de alumínio, resíduos gerados podem oferecer riscos à saúde humana e outros organismos vivos. ${ }^{25}$ No entanto, apesar de pouco difundido, a literatura também apresenta alguns estudos envolvendo novos materiais para eletrodos aptos a serem usados em eletrocoagulação, ${ }^{26}$ tais como grafite, $\mathrm{Pt}, \mathrm{PbO}_{2}, \mathrm{IrO}_{2}, \mathrm{SnO}_{2}-\mathrm{Sb}_{2} \mathrm{O}_{5}$,
$\mathrm{IrO}_{x}, \mathrm{RuO}_{2} \mathrm{e} \mathrm{TiO}{ }_{2},{ }^{3}$ com grande possibilidade de sucesso na aplicação da técnica de eletrocoagulação para tratamentos de água.

O acoplamento da eletrocoagulação com outras técnicas, principalmente empregando processos oxidativos avançados, é uma prática que vem sendo muito empregada atualmente. Muitos estudos presentes na literatura apontam que a eletrocoagulação já constitui um tratamento bastante eficiente quando empregada no tratamento de águas residuais. ${ }^{27-32}$ Entretanto, ao se realizar o acoplamento com outras técnicas, dentre elas a fotocatálise, ${ }^{33}$ ozonização $0^{34}$ e tratamento biológico, ${ }^{35}$ observa-se um efeito sinérgico muito significativo, de modo a atingir níveis de remoção mais altos ainda.

Neste trabalho, é apresentada uma análise crítica sobre a importância da técnica de eletrocoagulação/eletrofloculação como ferramenta para tratamento de águas residuárias, concentrando-se principalmente no emprego de novos eletrodos. Inicialmente, é realizada uma compilação dos estudos mais recentes envolvendo eletrocoagulação/eletrofloculação sobre eletrodos de Ferro e Alumínio. Adicionalmente, é apresentada uma visão holística sobre os novos materiais eletródicos com potencialidade inovadora para propor novos métodos de eletrocoagulação/eletrofloculação. Por fim, são abordadas, ainda neste trabalho, algumas soluções baseadas no acoplamento da técnica de eletrocoagulação/electrofloculação a outros métodos de tratamento com vistas a melhorar a eficiência na mitigação dos potenciais danos causados por águas residuárias e assim contribuir para a solução de problemas ambientais.

\section{ELETROFLOCULAÇÃO/ELETROCOAGULAÇÃO}

\section{Eletrodos convencionais}

A literatura reporta diversos estudos mostrando o sucesso da eletrofloculação quando aplicada na remoção de sólidos suspensos, ${ }^{5,36}$ microrganismos, ${ }^{37}$ algas,${ }^{38,39}$ corantes,,${ }^{5,40,41}$ corantes têxteis, ${ }^{42}$ detergentes, ${ }^{43}$ óleos, ${ }^{44,45}$ graxas ${ }^{45}$ e outros, em efluentes industriais. Nesse método, a geração de agentes floculantes in situ ocorre pela dissolução do ânodo, que por sua vez substitui a adição de agentes químicos floculantes (geração de íons; hidrólise dos cátions, desestabilização dos contaminantes) ${ }^{46}$ Concomitantemente, há a geração de bolhas de gás $\mathrm{H}_{2}$ durante a eletrólise da água no cátodo, que auxilia no processo de flotação dos contaminantes

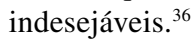

Os eletrodos convencionais ( $\mathrm{Al} \mathrm{e} \mathrm{Fe),} \mathrm{ao} \mathrm{serem} \mathrm{submetidos} \mathrm{à} \mathrm{uma}$ diferença de potencial, irão se dissolver, lançando, respectivamente, íons $\mathrm{Al}^{3+} \mathrm{e} \mathrm{Fe}^{2+} / \mathrm{Fe}^{3+}$ na solução. ${ }^{36}$ Os processos específicos envolvidos na formação dos agentes coagulantes referentes a cada material são mostrados a seguir.

As reações subsequentes à liberação de íons em solução são essenciais para formação do coagulante, cujos parâmetros controlam a eficiência do processo. Nessa etapa, há a hidrólise dos íons metálicos gerados $\left(\mathrm{M}(\mathrm{OH})_{\mathrm{n}(\mathrm{s})}\right)$, desestabilização da carga dos coloides, adsorção e/ou complexação de compostos orgânicos e metais pesados e reações de oxido-redução. Em relação à hidrólise dos íons metálicos, considere o caso em que o ânodo de sacrifício é de alumínio, por exemplo. Em solução, os íons $\mathrm{Al}^{3+}$ são passíveis de reações de hidrólise e formação de uma grande diversidade de espécies formadas, tais como: espécies monomérica $\mathrm{Al}(\mathrm{OH})^{2+}$ presente em meio ácido, espécies diméricas $\mathrm{Al}_{2}(\mathrm{OH})_{4}{ }^{2+}$, espécies poliméricas presentes em meio neutro $\mathrm{Al}_{3}(\mathrm{OH})_{4}{ }^{5+}, \mathrm{Al}_{4}(\mathrm{OH})_{8}{ }^{4+}, \mathrm{Al}_{5}(\mathrm{OH})_{13}{ }^{2+}, \mathrm{Al}_{6}(\mathrm{OH})_{12}{ }^{6+}$, $\mathrm{Al}_{10}(\mathrm{OH})_{22}{ }^{8+}, \mathrm{Al}_{13}(\mathrm{OH})_{32}{ }^{7+}$ e espécies monoméricas em meio alcalino $\mathrm{Al}(\mathrm{OH})_{3}, \mathrm{Al}(\mathrm{OH})_{4}{ }^{-15,47-50}$

De acordo com a literatura, ${ }^{51}$ quando as concentrações do íon metálico, neste caso $\mathrm{Al}^{3+}$, e do íon $\mathrm{OH}^{-}$são altas o suficiente para atingir o produto de solubilidade do respectivo hidróxido, neste caso 
$\mathrm{Al}(\mathrm{OH})_{3}$, há a formação do precipitado do hidróxido metálico. As espécies poliméricas formadas em solução durante o processo de eletrocoagulação são consideradas responsáveis pela eficiência da técnica na remoção dos poluentes. ${ }^{52}$

Em suma, o mecanismo de reação basicamente envolve a dissolução anódica do Alumínio metálico, quando submetido a uma densidade de corrente controlada, seguido pela hidrólise dos cátions polivalentes gerados. O hidróxido formado atua como agente coagulante, aprisionando sólidos suspensos, enquanto a eletrofloculação auxilia na remoção do poluente através da geração de bolhas de hidrogênio no cátodo e formação de agregados gás-coágulo que são direcionados para a superfície. ${ }^{53}$

A formação de camada passivante de óxido metálico $\left(\mathrm{Al}_{2} \mathrm{O}_{3}\right)$ aderente à superfície do eletrodo também ocorre durante a eletrocoagulação sobre eletrodos de $\mathrm{Al}$ e consiste em um problema relevante no uso desse material. Nesse caso, a formação destes filmes impede a subsequente transferência de carga no eletrodo e consequente dissolução do metal para geração do coagulante. ${ }^{54} \mathrm{Uma}$ das maneiras de contornar essa situação é adicionar certos ânions na solução, tais como íon $\mathrm{Cl}^{-}$, os quais podem promover a corrosão por pitting do filme. A desvantagem dessa estratégia é a maior dificuldade em promover a dissolução anódica nos sítios de corrosão durante processo de re-passivação. ${ }^{55}$

De forma análoga, a eletrofloculação usando eletrodos metálicos de Ferro processa-se pela aplicação de corrente elétrica capaz de promover a oxidação do ânodo (Equações 4 e 5), que uma vez submerso em meio aquoso, pode formar hidróxidos de $\mathrm{Fe}(\mathrm{II})$ e $\mathrm{Fe}$ (III) (Equações 6 e 7), seguido da formação de particulados pela desidratação dos hidróxidos segundo as Equações 8 a $11 .{ }^{56} \mathrm{O}$ processo, em geral, termina com várias outras reações descritas como processos de coagulação, floculação, oxidação, flotação e decantação dos contaminantes em suspensão.

Ânodo:

$$
\begin{aligned}
& \mathrm{Fe}_{(\mathrm{s})} \rightarrow \mathrm{Fe}_{(\mathrm{aq})}^{3+}+3 \mathrm{e}^{-} \\
& \mathrm{Fe}_{(\mathrm{s})} \rightarrow \mathrm{Fe}_{(\mathrm{aq})}^{2+}+2 \mathrm{e}^{-}
\end{aligned}
$$

Em solução:

$$
\begin{gathered}
\mathrm{Fe}_{(\mathrm{aq})}^{3+}+3 \mathrm{OH}^{-} \rightarrow \mathrm{Fe}(\mathrm{OH})_{3(\mathrm{~s})} \\
\mathrm{Fe}_{(\mathrm{aq})}^{2+}+2 \mathrm{OH}^{-} \rightarrow \mathrm{Fe}(\mathrm{OH})_{2(\mathrm{~s})} \\
2 \mathrm{Fe}(\mathrm{OH})_{3} \rightarrow \mathrm{Fe}_{2} \mathrm{O}_{3}+3 \mathrm{H}_{2} \mathrm{O} \\
\mathrm{Fe}(\mathrm{OH})_{2} \rightarrow \mathrm{FeO}+\mathrm{H}_{2} \mathrm{O} \\
2 \mathrm{Fe}(\mathrm{OH})_{3} \rightarrow \mathrm{Fe}(\mathrm{OH})_{2}+\mathrm{Fe}_{3} \mathrm{O}_{4}+4 \mathrm{H}_{2} \mathrm{O} \\
\mathrm{Fe}(\mathrm{OH})_{3} \rightarrow \mathrm{FeO}(\mathrm{OH})+\mathrm{H}_{2} \mathrm{O}
\end{gathered}
$$

O amplo uso desses eletrodos é justificado pelo baixo preço desses materiais e pela alta eficiência no quesito de dissolução anódica.

No entanto, nesse processo, o controle do potencial e/ou da densidade de corrente, cujo valor mais adequado depende de uma série de fatores tais como o tipo de matriz a ser tratada, o material eletródico e $\mathrm{pH},{ }^{46}$ é de alta relevância e é importante ressaltar que reações paralelas de oxidação de íons orgânicos e metálicos em solução, também passíveis de oxidação/redução durante o processo, podem ocorrer e perturbar a eficiência do processo.

De acordo com a literatura, ${ }^{57}$ um exemplo típico de reações de oxidação-redução ocorrentes no processo de eletrocoagulação é a redução de ânions nitrato no cátodo, ou ainda, a ocorrência de reações de oxidação por espécies formadas in situ, tais como íons sulfetos e bissulfeto, ${ }^{58}$ sobre eletrodos de alumínio, cujas principais reações são resumidas nas Equações 12-14 e 15-16, respectivamente.

$$
\begin{gathered}
3 \mathrm{NO}_{3(\mathrm{aq})}^{-}+3 \mathrm{H}_{2} \mathrm{O}_{(\mathrm{l})}+2 \mathrm{Al}_{(\mathrm{s})} \rightarrow 2 \mathrm{Al}_{(\mathrm{aq})}^{3+}+3 \mathrm{NO}_{2(\mathrm{aq})}^{-}+6 \mathrm{OH}_{(\mathrm{aq})}^{-} \\
\mathrm{E}_{\mathrm{red}}^{\mathrm{s}^{2}}=1,72 \mathrm{~V} \\
6 \mathrm{NO}_{3(\mathrm{aq})}^{-}+18 \mathrm{H}_{2} \mathrm{O}_{(\mathrm{l})}+10 \mathrm{Al}_{(\mathrm{s})} \rightarrow 10 \mathrm{Al}_{(\mathrm{aq})}^{3+}+3 \mathrm{~N}_{2(\mathrm{~g})}+36 \mathrm{OH}_{(\mathrm{aq})}^{-} \\
\mathrm{E}_{\mathrm{red}}^{0}=1,97 \mathrm{~V} \\
6 \mathrm{NO}_{3(\mathrm{aq})}^{-}+18 \mathrm{H}_{2} \mathrm{O}_{(\mathrm{l})}+8 \mathrm{Al}_{(\mathrm{s})} \rightarrow 8 \mathrm{Al}_{(\mathrm{aq})}^{3+}+3 \mathrm{NH}_{3(\mathrm{~g})}+27 \mathrm{OH}_{(\mathrm{aq})}^{-} \\
\mathrm{E}_{\mathrm{red}}^{0}=1,59 \mathrm{~V} \\
\mathrm{HS}_{(\mathrm{aq})}^{-}+\mathrm{OH}_{(\mathrm{aq})}^{-} \rightarrow \mathrm{S}_{(\mathrm{s})}^{0}+\mathrm{H}_{2} \mathrm{O}_{(1)}+2 \mathrm{e}^{-} \\
\mathrm{HS}_{(\mathrm{aq})}^{-}+9 \mathrm{OH}_{(\mathrm{aq})}^{-} \rightarrow \mathrm{SO}_{4(\mathrm{aq})}^{2-}+5 \mathrm{H}_{2} \mathrm{O}_{(\mathrm{l})}+8 \mathrm{e}^{-}
\end{gathered}
$$

O mecanismo de adsorção dos poluentes na superfície dos hidróxidos metálicos em solução é descrito pelos modelos de complexação superficial, que levam em conta, em suas formulações, tanto a adsorção química (pela formação de ligações entre íons e sítios ativos na superfície do adsorvente), quanto por interações eletrostáticas, que se baseiam na atração de íons e coagulante com superfícies carregadas positivamente e negativamente. ${ }^{59}$ Como exemplo pode-se citar a importância da formação de complexos no tratamento por eletrocoagulação/eletrofloculação de compostos húmicos. ${ }^{60}$ Nessa situação, a interação eletrostática entre os compostos húmicos e o hidróxido pouco solúvel é prioritária em $\mathrm{pH}$ entre $5 \mathrm{e}$ 6 , quando os compostos húmicos estão carregados negativamente enquanto hidróxidos de alumínio e ferro estão carregados positivamente. Isso facilita a remoção dos contaminantes da solução pela sedimentação dos coágulos e fácil separação durante processo de eletroflotação.

O fenômeno de adsorção mencionado é descrito por três modelos bem aceitos na literatura: i) Modelo da Camada Difusa; ii) Modelo da Capacitância Constante; iii) Modelo da Tripla Camada. ${ }^{61}$ Em todos esses modelos supracitados, as reações superficiais são originadas pela formação dos hidróxidos como superfícies sólidas anfotéricas capazes de reagir com espécies positivas ou negativas e, quando atuam como ligantes, resultam na formação de complexos superficiais específicos. A diferença entre os modelos consiste na maneira como cada um descreve a dupla camada elétrica e de qual maneira as mudanças na concentração do eletrólito suporte são incorporadas nos modelos. ${ }^{62}$ Um bom exemplo de reações de complexação para remoção de suspensões coloidais e substâncias orgânicas solúveis é o trabalho de Jin et al. ${ }^{63}$ Nesse trabalho, reporta-se que a formação do complexo alumínio-ácido húmico, gerado pela interação entre o grupo carboxila do ácido e os centros metálicos dos hidróxidos e poli hidróxidos gerados na eletrofloculação, é o principal fenômeno responsável pela remoção desses compostos do meio reacional.

Um outro processo paralelo de grande utilidade em processos de eletrocoagulação com $\mathrm{Al}$ é descrito por Emamjomeh et al.$^{64} \mathrm{Nesse}$ trabalho, íons fluoreto são removidos por reações subsequentes de complexação diretas com $\mathrm{Al}^{+3}$ gerados durante eletrocoagulação com eletrodos de alumínio. As seguintes reações de complexação seguido de precipitação na presença de íons sódios são propostas:

$$
\begin{gathered}
\mathrm{Al}^{3+}+6 \mathrm{~F}^{-} \rightarrow \mathrm{AlF}_{6}^{3-} \\
\mathrm{AlF}_{6}^{3-}+3 \mathrm{Na}^{+} \rightarrow \mathrm{Na}_{3} \mathrm{AlF}_{6}
\end{gathered}
$$

$\mathrm{O} \mathrm{pH}$ possui efeito primordial na reatividade dos sítios ativos na superfície do adsorvente pois interfere diretamente na sua carga por meio de reações de protonação e desprotonação de grupos funcionais superficiais. Adicionalmente, também interfere no 
mecanismo de precipitação e formação dos hidróxidos metálicos. Uma alternativa interessante para tratamento de rejeitos contendo $\mathrm{Cr}$ (VI) é a eletrocoagulação com ferro como ânodo de sacrifício em meio fortemente alcalino, ${ }^{65}$ no qual a precipitação de $\mathrm{Cr}(\mathrm{OH})_{3}$ ocorre diretamente em solução, envolvendo as seguintes reações:

$$
\begin{gathered}
\mathrm{Cr}_{2} \mathrm{O}_{7}^{2-}+6 \mathrm{e}^{-}+7 \mathrm{H}_{2} \mathrm{O} \rightarrow 2 \mathrm{Cr}^{3+}+14 \mathrm{OH}^{-} \\
\mathrm{Cr}_{2} \mathrm{O}_{7}{ }^{2-}+6 \mathrm{Fe}^{2+}+7 \mathrm{H}_{2} \mathrm{O} \rightarrow 2 \mathrm{Cr}^{3+}+6 \mathrm{Fe}^{3+}+14 \mathrm{OH}^{-} \\
\mathrm{Cr}_{(\mathrm{aq})}{ }^{3+}+3 \mathrm{OH}^{-} \rightarrow \mathrm{Cr}(\mathrm{OH})_{3(\mathrm{~s})}
\end{gathered}
$$

É oportuno salientar que essa técnica possui grande particularidade no tratamento de águas residuárias contendo grande quantidade de emulsões e outras dispersões coloidais. Compostos coloidais (particulados com diâmetro na faixa de $1 \mathrm{~nm}$ até $1 \mu \mathrm{m}$ ), ${ }^{66}$ uma vez presentes na matriz, podem adquirir carga superficial decorrente de: ionização de grupos funcionais $\left(-\mathrm{OH},-\mathrm{COOH}\right.$ ou- $\left.\mathrm{NH}_{2}\right)$, adsorção de íons em solução, dissolução de sólidos iônicos ou substituição isomórfica. A carga superficial adquirida induzirá um rearranjo de cargas na partícula, resultando na formação de uma Dupla Camada Elétrica (DCE) que estabiliza a partícula,${ }^{67}$ dificultando, algumas vezes, a etapa de coagulação esperada. Isso é, uma vez formada a dupla camada elétrica (DCE) em sistemas coloidais, o sistema atinge uma determinada estabilidade, a qual pode ser explicada pelo uso da teoria de Derjaguin-Landau-Verwey-Overbeek ou DLVO. Tal teoria leva em consideração a sobreposição das camadas difusas dos particulados, que possuem carga de mesmo sinal. Essa força de repulsão depende de vários fatores (como potencial de Stern e potencial Zeta) ${ }^{68}$ enquanto as forças atrativas dependem das interações de Van der Waals, geradas pela polarização elétrica instantânea induzida pela aproximação de particulados de mesma natureza, como mostrado nas Figuras 2 e 3.

Esse fenômeno é evidente no tratamento de emulsões (óleo/água), onde a orientação do dipolo das moléculas de água e o acúmulo de

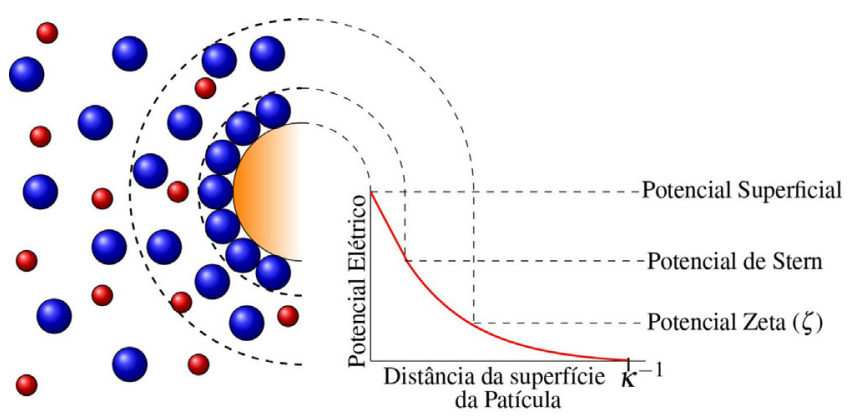

Figura 2. Representação da DCE de um coloide. Adaptado da ref. 69

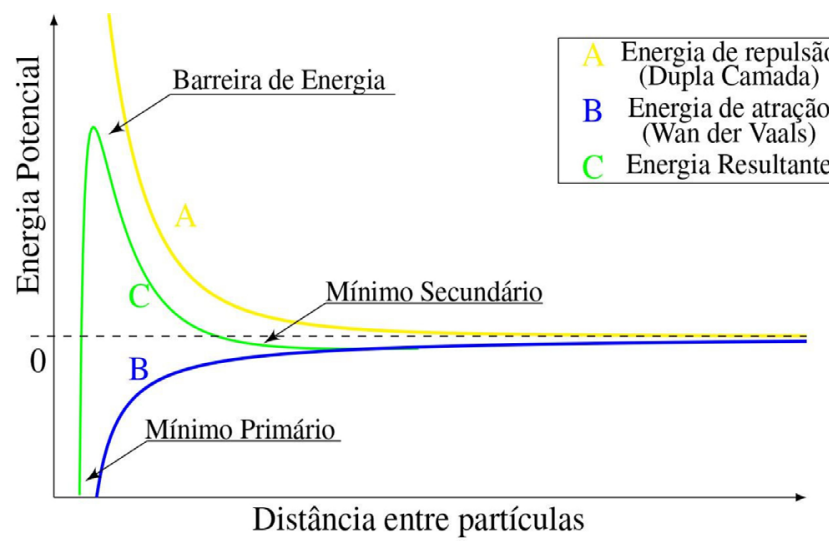

Figura 3. Perfil de energia potencial versus distância entre partículas em uma suspensão coloidal estável segundo a Teoria DLVO. Adaptado da ref. 70 ânions (principalmente $\left.\mathrm{OH}^{-}\right)^{71,72}$ na dupla camada confere carga negativa ao particulado. A extensão da camada difusa $\left(\kappa^{-1}\right)$ depende, dentre outras coisas, da força iônica da solução, de forma que quanto menor a força iônica, maior a extensão da camada, isto é, mais dispersa. ${ }^{73}$ A suspensão assim obtida é estável porque a presença de uma barreira de energia potencial impedirá a aproximação entre as partículas, dificultando o processo de coagulação.

A particularidade da eletrofloculação para o tratamento desses resíduos é consequência dos mecanismos que essa técnica possibilita, sendo os principais: Compressão da Dupla Camada Elétrica e Neutralização de Carga. ${ }^{74}$ A Compressão da Dupla Camada Elétrica consiste em aumentar a força iônica da solução por meio do aumento da concentração de íons, provenientes da dissolução do ânodo e da geração de íons hidroxila no cátodo, de forma a promover uma redução da extensão da camada difusa e, consequentemente, da força de repulsão entre as partículas. ${ }^{75}$ Uma vez que a interação de Van der Waals independe da força iônica do meio, ${ }^{76}$ a força de atração entre as partículas não se altera. Como resultado, a suspensão perde estabilidade, possibilitando a aproximação e a agregação dos particulados.

A Neutralização de Carga, por outro lado, consiste na neutralização da carga superficial das partículas coloidais por meio da adsorção de moléculas de carga oposta. ${ }^{74}$ No caso da eletrocoagulação, as moléculas de carga oposta serão os hidróxidos metálicos polinucleares formados pela hidrólise dos íons liberados pela dissolução anódica do eletrodo. ${ }^{77}$ Entretanto, caso haja excesso dos hidróxidos polinucleares, eles irão causar a reversão da carga dos particulados, restaurando a estabilidade do sistema. ${ }^{77,78}$

O sucesso da aplicação da técnica de eletrocoagulação/ eletrofloculação no tratamento de efluentes complexos é descrito na literatura. A Tabela 1 ilustra alguns dos principais trabalhos encontrados na literatura para remoção de alguns poluentes em meio aquoso usando a técnica de eletrocoagulação/eletrofloculação.

De modo geral, o sucesso da eletrocoagulação/eletrofloculação pode ser justificado principalmente pela adição controlada dos agentes coagulantes, em relação aos métodos de coagulação/flotação convencionais, por meio da geração in situ via dissolução de um dos eletrodos. No entanto, é importante ressaltar que essas características também controlam o tempo de vida dos eletrodos, danificados pela corrosão durante o processo. Assim a técnica se depara com a necessidade de substituição regular dos eletrodos devido a processos de passivação ou dissolução inerentes do processo, diminuindo a eficiência/economia do processo. O consumo energético algumas vezes também pode ser alto em relação aos métodos convencionais e o uso de eletrólitos para alta condutividade do efluente também deve ser considerado. Desse modo, estudos direcionados para o uso de novos materiais eletródicos ou combinação de métodos de tratamento acoplados à eletrofloculação tem norteado a busca por soluções menos dispendiosas e mais ambientalmente amigáveis.

\section{Eletrodos não convencionais}

A configuração dos eletrodos, bem como o material que os compõem, são importantes parâmetros que afetam drasticamente o desempenho do processo de eletrocoagulação. Como mostrado anteriormente, os eletrodos de Alumínio e Ferro são os materiais mais utilizados em aplicações para tratamento de água contaminada, tendo em vista o baixo preço desses materiais e a boa eficiência que proporcionam. Entretanto, devido às controvérsias quanto a utilização desses materiais, causadas pelos problemas associados a eles, a busca por eletrodos não convencionais que possam apresentar novas alternativas para tratamento por eletrocoagulação/eletrofloculação tem sido estimulada. ${ }^{15}$ 
Tabela 1. Estudos sobre o uso de Eletrocoagulação com eletrodos convencionais para o tratamento de diversos tipos de rejeitos

\begin{tabular}{|c|c|c|c|c|c|}
\hline Matriz estudada & Cátodo-Ânodo & Composto a ser removido & Remoção & Parâmetros & Referência \\
\hline $\begin{array}{l}\text { Efluente de fábrica de } \\
\text { óleo de palmeira }\end{array}$ & $\mathrm{Al}-\mathrm{Al}$ & COT & $75,4 \%$ & $\begin{array}{c}\mathrm{J}=56 \mathrm{~mA} \mathrm{~cm}^{-2} \\
\mathrm{t}=65 \mathrm{~min}\end{array}$ & 79 \\
\hline Água do mar & $\mathrm{Al}-\mathrm{Al}$ & COT & $70,8 \%$ & $\mathrm{~J}=22,4 \mathrm{~mA} \mathrm{~cm}^{-2}$ & 80 \\
\hline Solução sintética & Aço inoxidável-Al & $\begin{array}{c}\text { Corante Violeta de } \\
\text { Genciana }\end{array}$ & Cor: $100 \%$ & $\begin{array}{c}\mathrm{J}=250 \mathrm{~A} \mathrm{~m}^{-2} \\
\mathrm{t}=60 \mathrm{~min}\end{array}$ & 81 \\
\hline Efluente industrial & Latão-Al/Fe & COT & Cor: $99 \%$ & $\begin{array}{l}\mathrm{J}=20 \mathrm{~A} \mathrm{~m}^{-2} \\
\mathrm{t}=80 \mathrm{~min}^{-}\end{array}$ & 82 \\
\hline Efluente de decantador & $\mathrm{Al}-\mathrm{Al}$ & Fosfato & $99 \%$ & $\begin{array}{c}i=2 \mathrm{~A} \\
\mathrm{t}=60 \mathrm{~min}\end{array}$ & 83 \\
\hline $\begin{array}{l}\text { Solução sintética de } \\
\text { Fe(II) }\end{array}$ & $\mathrm{Al}-\mathrm{Al}$ & $\mathrm{Fe}(\mathrm{II})$ & $>97 \%$ & $\begin{array}{c}\mathrm{J}=2,5 \mathrm{~mA} \mathrm{~cm}^{-2} \\
\mathrm{t}=60 \mathrm{~min}\end{array}$ & 84 \\
\hline Água produzida & $\mathrm{Al}-\mathrm{Al}$ & Óleos & $90 \%$ & $\begin{array}{c}\mathrm{J}=45,5 \mathrm{~mA} \mathrm{~cm}^{-2} \\
\mathrm{t}=15 \mathrm{~min}\end{array}$ & 85 \\
\hline $\begin{array}{l}\text { Água presente em mina } \\
\text { de Urânio }\end{array}$ & $\begin{array}{l}\text { Aço inoxidável -Al/ } \\
\text { Aço inoxidável -Fe }\end{array}$ & Urânio & $\begin{array}{c}99,7 \% \\
\text { (Aço inoxidável -Fe) } \\
97,7 \% \\
\text { (Aço inoxidável -Al) }\end{array}$ & $\begin{array}{c}\mathrm{J}=70 \mathrm{~mA} \mathrm{~cm}{ }^{-2} \\
\mathrm{t}=120 \mathrm{~min}\end{array}$ & 86 \\
\hline $\begin{array}{l}\text { Solução sintética de } \\
\text { glifosfato }\end{array}$ & $\begin{array}{l}\mathrm{Al}-\mathrm{Al} / \\
\mathrm{Fe}-\mathrm{Fe}\end{array}$ & $\begin{array}{l}\text { Herbicida } \\
\text { (Glifosfato) }\end{array}$ & $\begin{array}{l}94,25 \%(\mathrm{Al}-\mathrm{Al}) \\
88,37 \%(\mathrm{Fe}-\mathrm{Fe})\end{array}$ & $\begin{array}{c}E=35 \mathrm{~V} \\
\mathrm{~J}=6 \mathrm{~mA} \mathrm{~cm}^{-2} \\
\mathrm{t}=60 \mathrm{~min}\end{array}$ & 87 \\
\hline $\begin{array}{l}\text { Rejeito de refinaria de } \\
\text { petróleo }\end{array}$ & $\mathrm{Fe}-\mathrm{Fe}$ & Selênio & $90 \%$ & $\begin{array}{c}\mathrm{J}=153 \mathrm{~A} \mathrm{~m}^{-2} \\
\mathrm{t}=360 \mathrm{~min}\end{array}$ & 88 \\
\hline Água salobra sintética & Aço inoxidável -Al & Sílica & $90,2 \%$ & $\begin{array}{l}\mathrm{i}=0,25 \mathrm{~A} \\
\mathrm{t}=20 \mathrm{~min}\end{array}$ & 89 \\
\hline Rejeito industrial & $\mathrm{Al}-\mathrm{Al}$ & Tinta de impressora & COT: $45 \%$ & $\begin{array}{c}\mathrm{J}=150 \mathrm{~A} \mathrm{~m}^{2} \\
\mathrm{t}=60 \mathrm{~min} \\
\mathrm{pH}=7,3\end{array}$ & 90 \\
\hline $\begin{array}{l}\text { Água de purificação de } \\
\text { biodiesel }\end{array}$ & $\mathrm{Al}-\mathrm{Al}$ & Turbidez & $80 \%$ & $\begin{array}{c}\mathrm{E}=12 \mathrm{~V} \\
\mathrm{i}=0,1 \mathrm{~A} \\
\mathrm{t}=240 \mathrm{~min}\end{array}$ & 91 \\
\hline $\begin{array}{l}\text { Efluente de } \\
\text { processamento de } \\
\text { minerais }\end{array}$ & $\mathrm{Al}-\mathrm{Al}$ & Sulfato, COT, $\mathrm{Ca}(\mathrm{II})$ & $\begin{array}{c}\text { Sulfato: } 93,14 \% \\
\text { COT: } 98,36 \% \\
\text { Ca(II): } 94,86 \% \\
\end{array}$ & $\begin{array}{c}\mathrm{J}=90,91 \mathrm{~mA} \mathrm{~cm}^{-2} \\
\mathrm{t}=120 \mathrm{~min}\end{array}$ & 92 \\
\hline Água de rio & $\mathrm{Al}-\mathrm{Al}$ & Acetominofeno & $60 \%$ & $\begin{array}{l}E=9 V \\
t=60 \min \end{array}$ & 93 \\
\hline Solução sintética & $\mathrm{Al}-\mathrm{Al}$ & Nitrato & $94,41 \%$ & $\begin{array}{c}\mathrm{E}=30 \mathrm{~V} \\
\mathrm{t}=150 \mathrm{~min}\end{array}$ & 94 \\
\hline $\begin{array}{l}\text { Água residual do } \\
\text { beneficiamento de } \\
\text { pescados }\end{array}$ & $\mathrm{Al}-\mathrm{Al}$ & $\begin{array}{c}\text { Fósforo } \\
\text { Óleos e graxas } \\
\text { Sólidos suspensos } \\
\text { Proteína }\end{array}$ & $\begin{array}{c}\text { Turbidez: } 96,9 \% \\
\text { DQO: } 93,3 \% \\
\text { Fósforo: } 88,5 \% \\
\text { Óleos e graxas: } 93,6 \%\end{array}$ & $\begin{array}{c}\mathrm{E}=15 \mathrm{~V} \\
\mathrm{i}=5 \mathrm{~A} \\
\mathrm{t}=25 \mathrm{~min}\end{array}$ & 95 \\
\hline Efluente de biodiesel & $\mathrm{Al}-\mathrm{Al}$ & Óleos e graxas & $99 \%$ & $\begin{array}{l}\mathrm{E}=3,5 \mathrm{~V} \\
\mathrm{t}=40 \mathrm{~min} \\
\mathrm{pH}=5,26\end{array}$ & 96 \\
\hline Solução sintética & $\mathrm{Al}-\mathrm{Al}$ & Cu e óleos & $\begin{array}{l}\text { Óleo: } 85 \% \\
\text { Cu: } 98 \%\end{array}$ & $\mathrm{~J}=1,5 \mathrm{~mA} \mathrm{~cm}-2$ & 97 \\
\hline $\begin{array}{l}\text { Efluente proveniente } \\
\text { da indústria de } \\
\text { processamento de coco }\end{array}$ & $\mathrm{Al}-\mathrm{Al}$ & COT & $68 \%$ & $\begin{array}{c}\mathrm{E}=3 \mathrm{~V} \\
\mathrm{t}=95 \mathrm{~min}\end{array}$ & 98 \\
\hline Suspensão de microalgas & $\begin{array}{l}\text { Aço inoxidável -Al } \\
\text { Aço inoxidável - } \mathrm{Fe}\end{array}$ & Microalgas & $\begin{array}{l}\text { 88\% (Aço inoxidável -Fe) } \\
73 \% \text { (Aço inoxidável -Al) }\end{array}$ & $\begin{array}{c}\mathrm{E}=1,1-1,3 \mathrm{~V} \\
\text { (Aço inoxidável -Fe) } \\
\mathrm{E}=0,8 \mathrm{~V} \\
\text { (Aço inoxidável -Al) }\end{array}$ & 99 \\
\hline
\end{tabular}

J: densidade de corrente elétrica, i: corrente elétrica, E: Potencial aplicado e t: tempo de reação.

Desse modo, são compilados na Tabela 2 alguns trabalhos relevantes sobre o uso de alguns eletrodos diferentes daqueles comumente usados a base de $\mathrm{Al} \mathrm{e} \mathrm{Fe,} \mathrm{com} \mathrm{o} \mathrm{intuito} \mathrm{de} \mathrm{comparar} \mathrm{de}$ modo crítico o desempenho de eletrodos não convencionais como ânodos de sacrifício na técnica de eletrocoagulação/eletrofloculação para o tratamento de água. Uma amostragem desses trabalhos mostra que diferentes arranjos de cátodos/ânodos são utilizados em sistemas de reatores para eletrocoagulação/eletrofloculação, 
Tabela 2. Estudos sobre o uso de Eletrocoagulação com eletrodos não convencionais para o tratamento de diversos tipos de rejeitos

\begin{tabular}{|c|c|c|c|c|c|}
\hline Matriz estudada & Cátodo-Ânodo & Composto a ser removido & Remoção & Parâmetros & Referência \\
\hline Solução sintética & Ti-Ti & As(III) & $58 \%$ & $\begin{array}{c}\mathrm{J}=0,65-1,53 \mathrm{~mA} \mathrm{~cm}^{-2} \\
\mathrm{t}=60 \mathrm{~min}\end{array}$ & 100 \\
\hline Rejeitos de laticínios & Aço-Aço & Óleos e graxas & $99 \%$ & $\begin{array}{c}\mathrm{J}=0,6 \mathrm{~mA} \mathrm{~cm}^{-2} \\
\mathrm{t}=20 \mathrm{~min}\end{array}$ & 101 \\
\hline Solução sintética & Aço inoxidável -Al (liga) & Fosfato & $99 \%$ & $\begin{array}{c}\mathrm{J}=0,2 \mathrm{~A} \mathrm{dm}^{-2} \\
\mathrm{t}=50 \mathrm{~min}\end{array}$ & 102 \\
\hline Água potável & $\mathrm{Zn}-\mathrm{Mg}$ & Ferro & $98,4 \%$ & $\begin{array}{c}\mathrm{J}=0,06 \mathrm{~A} \mathrm{dm}^{-2} \\
\mathrm{t}=60 \mathrm{~min}\end{array}$ & 103 \\
\hline Água potável & Aço inoxidável -Mg(liga) & Fluoreto & $96 \%$ & $\begin{array}{c}\mathrm{J}=0,06 \mathrm{~A} \mathrm{dm}^{-2} \\
\mathrm{t}=60 \mathrm{~min}\end{array}$ & 104 \\
\hline Solução sintética & Aço inoxidável -Al (liga) & Fosfato & $99 \%$ & $\begin{array}{c}\mathrm{J}=0,2 \mathrm{~A} \mathrm{dm}^{-2} \\
\mathrm{t}=50 \mathrm{~min}\end{array}$ & 102 \\
\hline Meio salino & Aço-Aço & Ftalatos em geral & $100 \%$ & $\begin{array}{c}\mathrm{J}=33-65 \mathrm{~mA} \mathrm{~cm}^{-2} \\
\mathrm{t}=10 \text { a } 15 \mathrm{~min}\end{array}$ & 105 \\
\hline Água potável & Aço inoxidável -Mg & Boro & $86,3 \%$ & $\begin{array}{c}\mathrm{J}=0,2 \mathrm{~A} \mathrm{dm}^{-2} \\
\mathrm{t}=180 \mathrm{~min}\end{array}$ & 106 \\
\hline Solução sintética & $\mathrm{Zn}-\mathrm{Zn}$ & Cádmio & $\begin{array}{l}97,8 \%(\mathrm{AC}) \\
96,9 \%(\mathrm{DC})\end{array}$ & $\begin{array}{c}\mathrm{J}=0,2 \mathrm{~A} \mathrm{dm}^{-2} \\
\mathrm{t}=150 \mathrm{~min}\end{array}$ & 107 \\
\hline Solução sintética & Al (liga)-Al (liga) & Cádmio & $\begin{array}{l}97,5 \%(\mathrm{AC}) \\
96,2 \%(\mathrm{DC})\end{array}$ & $\begin{array}{c}\mathrm{J}=0,2 \mathrm{~A} \mathrm{dm}^{-2} \\
\mathrm{t}=150 \mathrm{~min}\end{array}$ & 108 \\
\hline Água potável & Zn-Al (liga) & $\mathrm{Cr}$ & $98,2 \%$ & $\begin{array}{c}\mathrm{J}=0,2 \mathrm{~A} \mathrm{dm}^{-2} \\
\mathrm{t}=240 \mathrm{~min}\end{array}$ & 109 \\
\hline Rejeito sintético & Aço-Aço & Estrôncio & $93 \%$ & $\begin{array}{c}\mathrm{J}=8 \mathrm{~mA} \mathrm{~cm}^{-2} \\
\mathrm{t}=50 \mathrm{~min}\end{array}$ & 110 \\
\hline Resíduo têxtil & Aço-Aço & $\begin{array}{c}\text { Ácido Black } 1 \\
\text { Azul reativo } 4 \\
\text { Eosina Amarela }\end{array}$ & $\begin{array}{l}80 \% \\
56 \% \\
76 \% \\
\end{array}$ & $\begin{array}{l}\mathrm{i}=0,3 \mathrm{~A} \\
\mathrm{t}=12 \mathrm{~min}\end{array}$ & 111 \\
\hline Solução sintética & $\begin{array}{l}\mathrm{Zn}-\mathrm{Zn} \\
\mathrm{Cu}-\mathrm{Cu}\end{array}$ & As(III) & $\begin{array}{l}99,89 \%(\mathrm{Zn}-\mathrm{Zn}) \\
99,56 \%(\mathrm{Cu}-\mathrm{Cu})\end{array}$ & $\begin{array}{c}E=5 V \\
t=20 \min \end{array}$ & 112 \\
\hline Solução sintética & $\mathrm{Zn}-\mathrm{Mg}$ & $\mathrm{Mn}$ & $97,2 \%$ & $\begin{array}{c}\mathrm{J}=0,05 \mathrm{~A} \mathrm{dm}^{-2} \\
\mathrm{t}=100 \mathrm{~min}\end{array}$ & 113 \\
\hline Solução sintética & Aço inoxidável -Zn & Boro & $93,2 \%$ & $\begin{array}{c}\mathrm{J}=0,2 \mathrm{~A} \mathrm{dm}^{-2} \\
\mathrm{t}=210 \mathrm{~min}\end{array}$ & 114 \\
\hline $\begin{array}{l}\text { Amostras de lodo } \\
\text { fermentado }\end{array}$ & Mg-Mg & Fosfato & $98 \%$ & $\begin{array}{c}\mathrm{i}=0,05-0,2 \mathrm{~A} . \\
\mathrm{t}=120 \mathrm{~min}\end{array}$ & 115 \\
\hline Resíduo de bateria & Aço-Aço & $\begin{array}{l}\text { Chumbo } \\
\text { Zinco }\end{array}$ & $\begin{array}{l}93,3 \% \\
93,8 \%\end{array}$ & $\begin{array}{c}\mathrm{J}=6 \mathrm{~mA} \mathrm{~cm} \mathrm{~m}^{-2} \mathrm{e} \\
8 \mathrm{~mA} \mathrm{~cm}^{-2} \\
\mathrm{t}=30 \mathrm{~min}\end{array}$ & 116 \\
\hline Solução sintética & $\mathrm{Zn}-\mathrm{Mg}$ & Estrôncio e Césio & $\begin{array}{l}97,0 \%(\mathrm{Sr}) \\
96,8 \%(\mathrm{Cs})\end{array}$ & $\begin{array}{c}\mathrm{J}=0,08 \mathrm{~A} \mathrm{dm}^{-2} \\
\mathrm{t}=90 \mathrm{~min}\end{array}$ & 117 \\
\hline $\begin{array}{l}\text { Rejeito sintético de } \\
\text { moinho de azeite }\end{array}$ & Aço inoxidável -Zn & Compostos fenólicos & $\begin{array}{c}\text { Compostos } \\
\text { fenólicos: } 84,2 \% \\
\text { Carga orgânica: } 40,3 \%\end{array}$ & $\begin{array}{l}\mathrm{J}=250 \mathrm{~A} \mathrm{~m}^{-2} \\
\mathrm{t}=180 \mathrm{~min}\end{array}$ & 118 \\
\hline Efluente industrial & $\mathrm{Cu}-\mathrm{Cu}$ & COT & $56 \%$ & $\begin{array}{c}\mathrm{J}=14,3 \mathrm{~mA} \mathrm{~cm}^{-2} \\
\mathrm{t}=30 \mathrm{~min}\end{array}$ & 119 \\
\hline Efluente industrial & $\mathrm{Cu}-\mathrm{Cu}$ & $\begin{array}{l}\text { DQO, COT, Cor, } \\
\text { Turbidez. }\end{array}$ & $\begin{array}{c}\text { DQO: } 89 \% \\
\text { COT: } 48 \% \\
\text { Cor: } 97 \% \\
\text { Turbidez: } 91 \%\end{array}$ & $\begin{array}{l}\mathrm{i}=1-3 \mathrm{~A} \\
\mathrm{t}=50 \mathrm{~min}\end{array}$ & 120 \\
\hline $\begin{array}{l}\text { Efluente de destilaria a } \\
\text { base de arroz }\end{array}$ & $\mathrm{Cu}-\mathrm{Cu}$ & DQO, Cor & $\begin{array}{c}\text { DQO: } 80 \% \\
\text { Cor: } 65 \% \\
\end{array}$ & $\begin{array}{c}\mathrm{J}=89,3 \mathrm{~A} \mathrm{~m}^{-2} \\
\mathrm{t}=120 \mathrm{~min}\end{array}$ & 121 \\
\hline Água potável & $\mathrm{Cu}-\mathrm{Cu}$ & DQO, COT & $\begin{array}{c}\text { DQO: } 37,67 \% \\
\text { COT: } 27 \%\end{array}$ & $\begin{array}{c}\mathrm{J}=25 \mathrm{~mA} \mathrm{~cm}^{-2} \\
\mathrm{t}=300 \mathrm{~min}\end{array}$ & 122 \\
\hline Solução sintética & $(\mathrm{Fe} / \mathrm{Ni})-(\mathrm{Fe} / \mathrm{Ni})$ & Boro & $95 \%$ & $\begin{array}{c}\mathrm{J}=3,75 \mathrm{~mA} \mathrm{~cm}^{-2} \\
\mathrm{t}=60 \mathrm{~min}\end{array}$ & 123 \\
\hline $\begin{array}{l}\text { Influente de estação de } \\
\text { tratamento de água }\end{array}$ & $\mathrm{Mg}-\mathrm{Mg}$ & DQO, Nitrogênio total & $\begin{array}{c}\text { DQO: } 49 \% \\
\text { Nitrogênio total: } 21 \%\end{array}$ & $\begin{array}{c}\mathrm{i}=200 \mathrm{~mA}-3,8 \mathrm{~A} \\
\mathrm{t}=30 \mathrm{~min}\end{array}$ & 124 \\
\hline
\end{tabular}


Tabela 2. Estudos sobre o uso de Eletrocoagulação com eletrodos não convencionais para o tratamento de diversos tipos de rejeitos (cont.)

\begin{tabular}{|c|c|c|c|c|c|}
\hline Matriz estudada & Cátodo-Ânodo & Composto a ser removido & Remoção & Parâmetros & Referência \\
\hline Solução sintética & Aço inoxidável -Al(liga) & $\begin{array}{c}\text { Fosfato, } \mathrm{Zn}(\mathrm{II}) \text { e corante } \\
\text { Alaranjado II }\end{array}$ & $\begin{array}{c}\text { Fosfato: } 95-96 \% \\
\text { Zn(II): } 99 \% \\
\text { corante Alaranjado II: } \\
\text { 88-96\% }\end{array}$ & $\begin{aligned} \mathrm{J}= & 11,7 \mathrm{~mA} \mathrm{~cm}^{-2} \\
& \mathrm{t}=30 \mathrm{~min}\end{aligned}$ & 55 \\
\hline $\begin{array}{l}\text { Efluente de indústria de } \\
\text { impressão }\end{array}$ & Aço inoxidável -Cu & DQO, SST e óleos & $\begin{array}{c}\text { DQO: } 67 \% \\
\text { Sólidos suspensos } \\
\text { totais: } 24 \% \\
\end{array}$ & $\begin{array}{c}\mathrm{J}=14,21 \text { e } 28 \mathrm{~mA} \mathrm{~cm}^{-2} \\
\mathrm{t}=5-90 \mathrm{~min}\end{array}$ & 125 \\
\hline Resíduo têxtil & Aço-Aço & $\begin{array}{c}\text { Fosfatos } \\
\text { Orange II } \\
\text { Íons de zinco }\end{array}$ & $88 \%$ & $\begin{aligned} \mathrm{J}= & 11,7 \mathrm{~mA} \mathrm{~cm}^{-2} \\
& \mathrm{t}=30 \mathrm{~min}\end{aligned}$ & 126 \\
\hline $\begin{array}{l}\text { Resíduos da cultura de } \\
\text { pistache }\end{array}$ & $\begin{array}{l}\text { Diamante dopado } \\
\text { com boro-Aço }\end{array}$ & $\begin{array}{c}\text { Coriolus versicolor, } \\
\text { Funalia trogii, } \\
\text { Aspergillus carbonarius, } \\
\text { Penicillium glabrum }\end{array}$ & $90,1 \%$ & $\begin{array}{c}\mathrm{J}=50-300 \mathrm{~mA} \mathrm{~cm}^{-2} \\
\mathrm{t}=240 \mathrm{~min}\end{array}$ & 127 \\
\hline $\begin{array}{l}\text { Efluente de indústria de } \\
\text { impressão }\end{array}$ & $\begin{array}{l}\text { Aço inoxidável -Zn } \\
\text { Aço inoxidável -Ti }\end{array}$ & DQO & $\begin{array}{l}\text { 50\% (Aço inoxidável-Zn) } \\
47 \% \text { (Aço inoxidável-Ti) }\end{array}$ & $\begin{array}{c}\mathrm{J}=15 \mathrm{~mA} \mathrm{~cm}^{-2} \\
\mathrm{t}=90 \mathrm{~min}\end{array}$ & 128 \\
\hline Solução sintética & Ti-Ti & Ácido húmico & COT: $94 \%$ & $\begin{array}{c}\mathrm{J}=10 \mathrm{~mA} \mathrm{~cm}^{-2} \\
\mathrm{t}=90 \mathrm{~min}\end{array}$ & 129 \\
\hline Solução sintética & Aço inoxidável -Zn & Ureia & $66 \%$ & $\begin{array}{c}\mathrm{J}=21 \mathrm{~mA} \mathrm{~cm}^{-2} \\
\mathrm{t}=90 \mathrm{~min}\end{array}$ & 130 \\
\hline Solução sintética & $\mathrm{Pt}-\mathrm{Ni}$ & $\mathrm{Cr}(\mathrm{VI})$ & $99,5 \%$ & $\begin{array}{l}E=0,97 \mathrm{~V} \\
\mathrm{t}=20 \mathrm{~min}\end{array}$ & 131 \\
\hline
\end{tabular}

J: densidade de corrente elétrica, i: corrente elétrica, E: Potencial aplicado e t: tempo de reação.

em que os ânodos mais comuns são Ti, $\mathrm{Zn}, \mathrm{Cu}, \mathrm{Ni}$, aço inoxidável e Mg. Esses sistemas mostram alto desempenho na remoção de compostos orgânicos e metálicos em matrizes variadas. A seguir, descrevemos as principais contribuições de cada eletrodo usado como ânodo de sacrifício, para o avanço da técnica como alternativa no desenvolvimento de novos métodos para tratamento de amostras ambientais.

A análise crítica da Tabela 2 permite inferir que existe uma quantidade significativa de eletrodos não convencionais, os quais apresentam excelentes desempenhos frente a diversas matrizes compostas por diferentes espécies químicas e biológicas. Pode-se destacar o eletrodo do trabalho de Şengil et al., ${ }^{101}$ o qual conferiu uma remoção de $99 \%$ de óleo e graxas após 20 minutos de tratamento por eletrocoagulação a uma densidade de corrente de $0,6 \mathrm{~mA} \mathrm{~cm}{ }^{-2}$. Verifica-se que este eletrodo conferiu um dos menores gastos energéticos ao se comparar com os demais. Pode-se ainda destacar o eletrodo de liga de aço feito por Kabdaşli et al. ${ }^{105}$ o qual possibilitou $100 \%$ de remoção de ftalatos em geral em meio salino.

\section{Aço inoxidável e outras ligas metálicas}

O aço inoxidável é uma liga metálica composta basicamente de ferro, carbono, níquel e cromo, e tem sido explorado como ânodo em eletrocoagulação pela sua alta resistência à corrosão durante processos de oxidação. ${ }^{132}$ Nesse contexto, o uso de ânodos de aço inoxidável tem sido uma alternativa interessante para os problemas verificados no uso de $\mathrm{Fe}$ e $\mathrm{Al}$, uma vez que a presença de crômio em sua composição facilita a passivação parcial do eletrodo, aumentando a formação da camada protetora de óxidos no eletrodo e, consequentemente, minimizando a formação de particulados de óxido de ferro no meio, ${ }^{126}$ os quais conferem uma coloração amarelada à solução. ${ }^{133,134}$ Em contrapartida, a maior formação do filme passivante pode interferir diretamente na quantidade formada do coagulante e, consequentemente, na diminuição da eficácia do tratamento. ${ }^{126}$ A Tabela 3 ilustra alguns trabalhos relevantes usando ânodos baseados em ligas de aço inoxidável para diferentes aplicações de eletrofloculação.
Os pesquisadores Dura et al. ${ }^{126}$ compararam a eficiência de duas ligas com diferentes concentrações de crômio e concluíram que a AISI 420 apresenta boa dissolução anódica e eficiência na remoção de fosfato, íons zinco e corante Alaranjado II. O desempenho é próximo àquele observado para ânodos de ferro puro, porém com reduzida formação de óxidos indesejados. No estudo de Mahmad et al. ${ }^{135} \mathrm{o}$ ânodo de aço inoxidável apresentou, em comparação com ânodo de alumínio, maior eficiência na remoção de crômio do rejeito, porém uma menor eficiência na remoção de turbidez. No trabalho de Murthy et al., ${ }^{110}$ observa-se que o processo de eletrocoagulação com eletrodos de aço inoxidável foi capaz de remover $93 \%$ de $\mathrm{Sr}$ (II), enquanto uma remoção de apenas $77 \%$ foi observada quando testado em eletrodos de alumínio. Alguns pesquisadores têm demonstrado que o aço inoxidável pode ser um bom material quando usado como cátodo em processos com ânodos de $\mathrm{Fe}$ ou $\mathrm{Al}$, influenciando a velocidade da passivação desses eletrodos. . $^{3,136}$

Estudos recentes têm investigado o desempenho de ligas de alumínio como ânodos de sacrifício no processo de eletrofloculação como alternativa para contornar os efeitos de passivação observado nos ânodos de alumínio convencionais. Os metais utilizados na fabricação dessas ligas, geralmente zinco, magnésio ou índio, são capazes de ativar o alumínio, isso é, acelerar a formação de rachaduras no filme de óxido $\left(\mathrm{Al}_{2} \mathrm{O}_{3}\right)$ aderido à superfície do eletrodo, ${ }^{54}$ permitindo que a dissolução anódica seja contínua durante o processo de dissolução do alumínio na liga. ${ }^{137,138} \mathrm{O}$ uso de ligas de alumínio contendo Zn (1-4\%), In (0,006-0,025\%), Fe $(0,15 \%)$ e Si $(0,15 \%)$ como ânodos em sistemas com cátodo de aço inoxidável também foi investigada para remediação de água contaminada por fosfato em processos de eletrofloculação. ${ }^{102}$ Sob condições otimizadas de $\mathrm{pH}=7,0$ e densidade de corrente $0,2 \mathrm{~A} \mathrm{dm}^{-2}$, o sistema apresentou uma eficiência de remoção de $99 \%$ quando a liga de alumínio foi utilizada, um resultado superior em relação ao obtido com o uso de ânodos de alumínio puro (remoção de $85 \%$ ). Ligas de alumínio com magnésio e zinco (Mg-Al-Zn) também foram utilizadas como ânodo de sacrifício ${ }^{104}$ no estudo da eletrofloculação de solução contaminada por fluoreto. Sob condições otimizadas, o método alcançou a remoção 
Tabela 3. Estudos sobre o uso de Eletrocoagulação com eletrodos de aço para o tratamento de diversos tipos de rejeitos

\begin{tabular}{|c|c|c|c|c|c|}
\hline Matriz estudada & Cátodo - Ânodo & Material a ser removido & Remoção & Parâmetros & Referência \\
\hline Rejeitos de laticínios & Aço-Aço & Óleos e graxas & $99 \%$ & $\begin{array}{c}\mathrm{J}=0,06 \mathrm{~A} \mathrm{dm}^{-2} \\
\mathrm{t}=60 \mathrm{~min}\end{array}$ & 101 \\
\hline Meio salino & Aço-Aço & Ftalatos em geral & $100 \%$ & $\begin{array}{c}\mathrm{J}=33-65 \mathrm{~mA} \mathrm{~cm}^{-2} \\
\mathrm{t}=10 \mathrm{a} 15 \mathrm{~min}\end{array}$ & 105 \\
\hline Rejeito sintético & Aço-Aço & Estrôncio & $93 \%$ & $\begin{array}{c}\mathrm{J}=8 \mathrm{~mA} \mathrm{~cm}^{-2} \\
\mathrm{t}=50 \mathrm{~min}\end{array}$ & 110 \\
\hline Resíduo têxtil & Aço-Aço & $\begin{array}{c}\text { Ácido Black } 1 \\
\text { Azul reativo } 4 \\
\text { Eosina Amarela }\end{array}$ & $\begin{array}{l}80 \% \\
56 \% \\
76 \% \\
\end{array}$ & $\begin{array}{l}\mathrm{i}=0,3 \mathrm{~A} \\
\mathrm{t}=12 \mathrm{~min}\end{array}$ & 111 \\
\hline Resíduo de bateria & Aço-Aço & $\begin{array}{l}\text { Chumbo } \\
\text { Zinco }\end{array}$ & $\begin{array}{l}93,3 \% \\
93,8 \%\end{array}$ & $\begin{array}{c}\mathrm{J}=6 \mathrm{~mA} \mathrm{~cm}{ }^{-2} \text { e } 8 \mathrm{~mA} \\
\mathrm{~cm}^{-2} \\
\mathrm{t}=30 \mathrm{~min}\end{array}$ & 116 \\
\hline Resíduo têxtil & Aço-Aço & $\begin{array}{c}\text { Fosfatos } \\
\text { Orange II } \\
\text { Íons de zinco }\end{array}$ & $88 \%$ & $\begin{array}{c}\mathrm{J}=11,7 \mathrm{~mA} \mathrm{~cm}^{-2} \\
\mathrm{t}=30 \mathrm{~min}\end{array}$ & 126 \\
\hline $\begin{array}{l}\text { Resíduos da cultura de } \\
\text { pistache }\end{array}$ & $\begin{array}{l}\text { Diamante dopado com } \\
\text { boro-Aço }\end{array}$ & $\begin{array}{c}\text { Coriolus versicolor, Fu- } \\
\text { nalia trogii, Aspergillus } \\
\text { carbonarius, Penicillium } \\
\text { glabrum }\end{array}$ & $90,1 \%$ & $\begin{array}{c}\mathrm{J}=50-300 \mathrm{~mA} \mathrm{~cm}-2 \\
\mathrm{t}=240 \mathrm{~min}\end{array}$ & 127 \\
\hline
\end{tabular}

J: densidade de corrente elétrica, i: corrente elétrica e t: tempo de reação.

de $96 \%$ de fluoreto em solução. Ligas de Al- Zn-In, nas mesmas condições experimentais, também mostraram ótimos resultados para remoção de crômio (98,2\%), e corante Alaranjado II (96\%), após 30 minutos de tratamento por eletrofloculação ${ }^{109}$ e desempenho superior em comparação com a liga $\mathrm{Al}-\mathrm{Mg}$, a qual promoveu a remoção de $88-93 \%$ de fosfato, $96 \%$ de $\mathrm{Zn}^{2+}$ e $50-60 \%$ do corante Alaranjado II. ${ }^{55}$

\section{Cobre}

O uso de cobre como ânodo de sacrifício baseia-se na facilidade da reação de oxidação de $\mathrm{Cu}$ metálico durante o processo de eletrocoagulação (Equação 22). Os íons $\mathrm{Cu}$ (II) liberados formam o complexo hexa(aqua)cobre (II) (Equação 23), o qual, em contato com íons $\mathrm{OH}^{-}$produzidos pela redução da água no cátodo, formam o agente coagulante hidróxido de cobre (II) (Equação 24). ${ }^{139}$ Em meio alcalino, há a subsequente desidratação do hidróxido de cobre (II), formando óxido de cobre (II) (Equações 25 e 26), de acordo com as reações propostas por Cudennec e Lecerf: ${ }^{140}$

$$
\begin{gathered}
\mathrm{Cu}_{(\mathrm{s})} \rightleftharpoons \mathrm{Cu}_{(\mathrm{aq})}^{2+}+2 \mathrm{e}^{-} \quad \mathrm{E}_{\text {red }}^{0}=+0,34 \mathrm{~V} \\
\mathrm{Cu}_{(\mathrm{aq})}^{2+}+6 \mathrm{H}_{3} \mathrm{O}_{(\mathrm{aq})}^{+} \rightarrow\left[\mathrm{Cu}\left(\mathrm{H}_{2} \mathrm{O}\right)_{6}\right]_{(\mathrm{aq})}^{2+}+6 \mathrm{H}_{(\mathrm{aq})}^{+} \\
{\left[\mathrm{Cu}\left(\mathrm{H}_{2} \mathrm{O}\right)_{6}\right]_{(\mathrm{aq})}^{2+}+2 \mathrm{OH}_{(\mathrm{aq})}^{-} \rightarrow \mathrm{Cu}(\mathrm{OH})_{2(\mathrm{~s})}+6 \mathrm{H}_{2} \mathrm{O}_{(\mathrm{l})}} \\
\mathrm{Cu}(\mathrm{OH})_{2(\mathrm{~s})}+2 \mathrm{OH}_{(\mathrm{aq})}^{-} \rightarrow \mathrm{Cu}(\mathrm{OH})_{4(\text { aq })}^{2-} \\
\mathrm{Cu}(\mathrm{OH})_{4(\mathrm{aq})}^{2-} \rightleftharpoons \mathrm{CuO}_{(\mathrm{s})}+2 \mathrm{OH}_{(\mathrm{aq})}^{-}+\mathrm{H}_{2} \mathrm{O}_{(\mathrm{l})}
\end{gathered}
$$

Estudos de Hernández et al. ${ }^{122}$ demonstraram que a eletrofloculação com ambos os eletrodos (ânodo e cátodo) de cobre promoveram a redução de apenas $38 \%$ de demanda química de oxigênio (DQO) e $27 \%$ do carbono orgânico total (COT), quando aplicados no tratamento de águas residuárias de indústria de bebidas. Em condições otimizadas de $\mathrm{pH}=8$ e densidade de corrente de $68 \mathrm{~mA} \mathrm{~cm}^{-2}$, observa-se baixa eficiência, que é associada à alta complexação da matéria orgânica com íons de cobre formados em solução. De acordo com os autores, a concentração de cobre em solução alcançou o valor de $47,4 \mathrm{mg} \mathrm{L}^{-1}$ na água tratada. No entanto, García-García et al. ${ }^{120}$ têm demonstrado que eletrodos de cobre, quando usados em processo de eletrocoagulação em condições otimizadas em $\mathrm{pH}=4$ seguido de eletro-oxidação, podem ser uma excelente ferramenta para tratamento de rejeito industrial. Após o tratamento com eletrodos de cobre, alcançou-se $89 \%$ na remoção de demanda química de oxigênio e $97 \%$ da coloração foi obtida em $\mathrm{pH}=4$. Os autores sugerem que a alta concentração de íons $\mathrm{CO}_{3}{ }^{2-}, \mathrm{SO}^{2-}, \mathrm{PO}^{3-}$ e $\mathrm{Cl}^{-}$no efluente conferem estabilidade química ao processo de eletrocoagulação com eletrodos de cobre pela sua capacidade de complexação.

O estudo da eletrocoagulação com ânodo de cobre foi demonstrado ser uma alternativa eficiente para remoção de partículas de grafeno em suspensões ácidas. Os íons $\mathrm{Cu}^{2+}$, gerados sob corrente alternada, adsorvem especificamente, formando filmes de grafeno ${ }^{141}$ na superfície com grande possibilidade de serem utilizados em aplicações anticorrosivas e na fabricação de dispositivos eletrônicos. Os estudos ainda reportam que o uso de corrente alternada durante a eletrocoagulação minimiza a drástica corrosão do ânodo devido à oxidação, aumentando o tempo de vida do eletrodo.

No entanto, embora o eletrodo de $\mathrm{Cu}$ apresente grande possibilidade de aplicação como ânodo de sacrifício em eletrofloculação, sua potencialidade tem sido limitada pela possibilidade de formar resíduos indesejados na água tratada. Isso é, apesar do cobre ser um nutriente essencial para o desenvolvimento de plantas e funcionamento dos organismos vivos, quando presente em quantidades excessivas na água é considerado um contaminante com potencial toxicidade,,$^{23,142,143}$ que deve ser evitado.

\section{Níquel}

O uso de eletrodos de níquel em métodos de eletrofloculação para tratamento de água é pouco reportado na literatura. Em um estudo mais recente, Wang et al., ${ }^{131}$ demonstraram que eletrodos porosos de níquel recobertos por nanofolhas de $\mathrm{NiO}$ se mostraram adequados para remoção de $\mathrm{Cr}$ (VI) em águas residuárias usando o método de eletrocoagulação. De acordo com os autores, o uso de Ni metálico como eletrodo na eletrofloculação fundamenta-se na geração de $\mathrm{NiO}$ e $\mathrm{NiOOH}$ sob potencial anódico controlado em $0,97 \mathrm{~V}$ vs. ERH, conforme mostrado nas Equações 27 e 28 . A remoção de Crômio (VI) ocorre pela sua redução a Cr(III) no cátodo, seguido da subsequente co-precipitação de $\mathrm{Cr}(\mathrm{OH})_{3}$ nos flocos de $\mathrm{Ni}(\mathrm{OH})_{2}$. 
O método alcançou remoção de $99,5 \%$ do poluente danoso à saúde humana em 20 minutos de tratamento.

$$
\begin{gathered}
\mathrm{Ni}+\mathrm{OH}^{-} \rightarrow \mathrm{Ni}(\mathrm{OH})_{2}+2 \mathrm{e}^{-} \\
\mathrm{NiO}+\mathrm{OH}^{-} \rightarrow \mathrm{NiOOH}+\mathrm{e}^{-}
\end{gathered}
$$

\section{Magnésio}

O uso de magnésio em processos eletroquímicos e aplicação em tratamento de água data de 1963, quando o pesquisador E. Føyn testou a eletrólise de uma mistura de água do mar e rejeitos na presença de sais de magnésio para desinfecção e remoção de orgânicos. ${ }^{144}$ Sob aplicação de corrente controlada ao sistema, íons cloreto foram oxidados a cloro gasoso no ânodo e a geração de hidroxilas, devido a redução da água no cátodo, promoveu a formação de $\mathrm{Mg}(\mathrm{OH})_{2(\mathrm{~s})} \mathrm{O}$ processo apresentou boa eficiência na remoção de fósforo, nitrogênio e compostos orgânicos, mas foi considerado caro em relação a outros processos disponíveis na época.

O uso de magnésio em como ânodo e ferro galvanizado como cátodo em eletrofloculação é descrito por Vasudevan et al., ${ }^{103}$ para a remoção de ferro da água potável. Nesse arranjo de reator, magnésio é usado como ânodo e ferro galvanizado como cátodo. Os experimentos otimizados demonstraram eficiência de remoção de $98 \%$ sob densidade de corrente de $0,06 \mathrm{~A} \mathrm{dm}^{-2}$, em solução corrigida para pH 6,0. Na reação, eletrodos de magnésio, como ânodos de sacrifício, ${ }^{145}$ são responsáveis pela formação de íons $\mathrm{Mg}^{2+}$ devido à dissolução de Magnésio metálico como ânodo $\left(E^{0}=-2,38 \mathrm{~V}\right.$ vs. ENH) de acordo com a Equação 29 e 30 . Em solução, os íons $\mathrm{Mg}^{2+}$ são precipitados com íons hidroxila gerados no cátodo formando o hidróxido insolúvel (Equação 31), que atua como agente coagulante.

O método é descrito como um bom método para a remoção de ferro, uma vez que há adsorção de ferro formando uma cobertura em monocamada de moléculas adsorvidas no coagulante. $\mathrm{O}$ processo de adsorção seguiu um modelo de cinética de segunda ordem.

$$
\begin{aligned}
& \mathrm{Mg} \rightarrow \mathrm{Mg}^{+}+\mathrm{e}^{-} \\
& \mathrm{Mg}^{+}+\mathrm{H}_{2} \mathrm{O} \rightarrow \mathrm{Mg}^{2+}+\mathrm{OH}^{-}+0,5 \mathrm{H}_{2}
\end{aligned}
$$

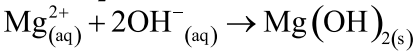

Os autores Hug et al. ${ }^{146}$ também mostram o uso de magnésio eletroquimicamente dissolvido a partir de um eletrodo de magnésio sacrificial para remoção de fosfatos. A remoção de fosfato atinge eficiência de corrente de $118 \%$ na presença de solução amoniacal, de acordo com a Equação 32, sob densidade de corrente de $5,5 \mathrm{~mA} \mathrm{~cm}^{-2}$. A remoção e recuperação de fosfato de rejeitos pela precipitação de estruvita utilizando este método também é descrita por outros autores. ${ }^{115,145,146}$

$\mathrm{Mg}^{2+}+\mathrm{NH}_{4}^{+}+\mathrm{H}_{\mathrm{n}} \mathrm{PO}_{4}^{3-\mathrm{n}}+6 \mathrm{H}_{2} \mathrm{O} \rightarrow \mathrm{MgNH}_{4} \mathrm{PO}_{4} \cdot 6 \mathrm{H}_{2} \mathrm{O}+\mathrm{nH}^{+}$

\section{Titânio}

A eletrocoagulação pelo uso de titânio (Ti) como substrato de sacrifício tem sido pouco explorada. O método baseia-se na dissolução de placas de Ti que, quando submetidas a corrente elétrica ou alto potencial em meio aquoso, pode gerar íons $\mathrm{Ti}^{4+}$, que formam agente coagulante relevante após reações sucessivas de hidrólise e geração de hidróxidos e polihidróxidos, de acordo com as Equações 33-38.

Ânodo:

$$
\begin{gathered}
\mathrm{Ti} \rightarrow \mathrm{Ti}^{3+}+3 \mathrm{e}^{-} \\
\mathrm{Ti}^{3+} \rightarrow \mathrm{Ti}^{4+}+\mathrm{e}^{-} \\
2 \mathrm{Ti}^{3+}+3 \mathrm{H}_{2} \mathrm{O} \rightarrow \mathrm{Ti}_{2} \mathrm{O}_{3}+6 \mathrm{H}^{+}
\end{gathered}
$$

$$
\begin{gathered}
\mathrm{Ti}^{4+}+2 \mathrm{H}_{2} \mathrm{O} \rightarrow \mathrm{TiO}_{2}+4 \mathrm{H}^{+} \\
\mathrm{TiO}^{2+}+6 \mathrm{OH}^{-}+2 \mathrm{e}^{-} \rightarrow \mathrm{Ti}(\mathrm{OH})_{4}+\mathrm{H}_{2}+3 \mathrm{O}^{2-}
\end{gathered}
$$

Cátodo:

$$
2 \mathrm{H}_{2} \mathrm{O}+2 \mathrm{e}^{-} \rightarrow \mathrm{H}_{2(\mathrm{~g})}+2 \mathrm{OH}^{-}
$$

O processo é similar ao princípio fundamental envolvido na construção de materiais nanoestruturados de $\mathrm{TiO}_{2}$ por métodos eletroquímicos amplamente divulgados na literatura. ${ }^{147}$ Simultaneamente, a redução da água no cátodo (Equação 39) é responsável pela geração de microbolhas de gás hidrogênio que age como agente eletrofloculante no processo, melhorando a agregação de partículas e desestabilização de contaminantes em solução. O processo tem se mostrado adequado nos processos de eletrocoagulação/eletrofloculação com precipitação ou flotação de poluentes e grande potencialidade na purificação de águas residuárias. ${ }^{148}$

De acordo com Chen et al.,${ }^{148}$ o uso de ânodo de titânio no processo de eletrofloculação pode ser bastante interessante. De acordo com os autores, a espécie $\mathrm{TiO}^{2+}$ é formada in situ após oxidação de $\mathrm{Ti}$, e $\mathrm{TiO}_{2} \cdot \mathrm{H}_{2} \mathrm{O}$ ou $\mathrm{Ti}(\mathrm{OH})_{4}$ após formação de íons $\mathrm{OH}^{-}$ no cátodo, onde ocorre a eletrólise da água $\left(\mathrm{H}_{2} \mathrm{O}+2 \mathrm{e}^{-} \rightarrow \mathrm{OH}^{-}+\mathrm{H}_{2}\right)$, o qual atuará como agente coagulante no processo. Isso é, durante o processo de eletrofloculação sobre Ti há a geração de espécies $\mathrm{Ti}^{3+}$ e $\mathrm{Ti}^{4+}$ no ânodo metálico (Equação 36 e 37), que pode formar hidróxidos capazes de adsorver materiais orgânicos por carga ou efeitos de superfície, levando os contaminantes a coagular. No entanto, o processo da eletrofloculação usando Ti como agente coagulante é altamente dependente de características físico-químicas do efluente (natureza, composição e concentração dos poluentes, condutividade da solução, $\mathrm{pH}$, células eletroquímicas (tamanho / área e distância dos eletrodos), tempo de eletrólise, corrente e material dos eletrodos. ${ }^{129}$

Shon et al. ${ }^{149}$ têm usado eletrodos de titânio (Ti) para o tratamento de água produzida de petróleo, otimizando parâmetros importantes tais como $\mathrm{pH}$ inicial da solução, densidade de corrente, natureza e força iônica do eletrólito. Além disto, têm demonstrado que o rejeito de $\mathrm{TiO}_{2}$ gerado após tratamento por eletrofloculação pode ser calcinado a $600{ }^{\circ} \mathrm{C}$ para produzir um fotocatalisador de $\mathrm{TiO}_{2}$ com características funcionais adaptáveis a processos fotocatalíticos. Após utilizar o fotocatalisador sintetizado no processo de degradação de acetaldeído, os pesquisadores constataram que a presença de carbono e fósforo na composição de $\mathrm{TiO}_{2}$ gerado no processo melhoram seu desempenho fotocatalítico frente ao uso do catalisador comercializado como $\mathrm{P}-25 \mathrm{TiO}_{2}$ quando submetido a irradiação UV/Vis, por exemplo.

Em um estudo mais recente, El-Ghenymy et al. ${ }^{129}$ têm demonstrado que a corrosão do Ti durante o processo de eletrofloculação e a formação de filmes passivantes durante a formação de óxidos pode influenciar fortemente a velocidade de corrosão do material e assim aumentar o tempo de eletrofloculação. Isto é, a formação de íons $\mathrm{Ti}^{3+} /$ $\mathrm{Ti}^{4+}$ durante a eletrodissolução de titânio sugere a formação de um filme passivante de óxido $\left(\mathrm{Ti}_{2} \mathrm{O}_{3}\right.$ e $\left.\mathrm{TiO}_{2}\right)$ na superfície do eletrodo, que poderia inibir posteriores corrosões importantes para o processo de eletrocoagulação. No entanto, essa limitação pode ser minimizada pelo uso de íons cloreto em solução que podem dissolver o óxido passivante formando complexos solúveis de $\mathrm{Ti}_{\mathrm{x}} \mathrm{O}_{\mathrm{y}} \mathrm{Cl}_{2}$ (Equação 40). Esse intermediário, quando formado, diminui a influência do óxido na superfície e assim interferir menos acentuadamente na dissolução anódica, como descrito por El-Ghenymy et al. ${ }^{106}$ Escrivà-Cerdán et al.,${ }^{125}$ e Liu et al. ${ }^{126}$ Desse modo, em meio de íons cloreto, há um aumento na velocidade de corrosão atribuído a eletrodissolução do óxido formado na superfície do eletrodo. 
Dissolução dos óxidos de titânio em meio de cloreto:

$$
\mathrm{Ti}_{x} \mathrm{O}_{y}+2 \mathrm{Cl}^{-} \rightarrow \mathrm{Ti}_{x} \mathrm{O}_{y} \mathrm{Cl}_{2}+2 \mathrm{e}^{-}
$$

A Figura 4 mostra uma representação esquemática das reações envolvidas no processo de eletrocoagulação com eletrodos de titânio, as quais foram discutidas anteriormente. No cátodo, a equação de reação de eletrólise da água foi mostrada, enquanto no ânodo foram mostrados os vários estágios das reações anódicas do processo: eletrodissolução do ânodo de sacrifício (parte superior do eletrodo), que leva a geração de íons $\mathrm{Ti}^{3+}$ em solução, os quais podem reagir com água, formando íons $\mathrm{H}^{+}$e óxido de titânio (III), e/ou podem ser oxidados a íons $\mathrm{Ti}^{4+}$ e posteriormente reagirem com água, formando íons $\mathrm{H}^{+}$e dióxido de titânio. O óxido de titânio (III) e o dióxido de titânio formam uma camada protetora sobre o eletrodo (camada escura na parte central do ânodo), impedindo o prosseguimento do processo. Na presença de íons cloreto, a camada de óxidos é dissolvida, como indicado pelo desaparecimento gradual da camada escura, possibilitando o prosseguimento do processo, resultando na formação do hidróxido de titânio (parte inferior do esquema).

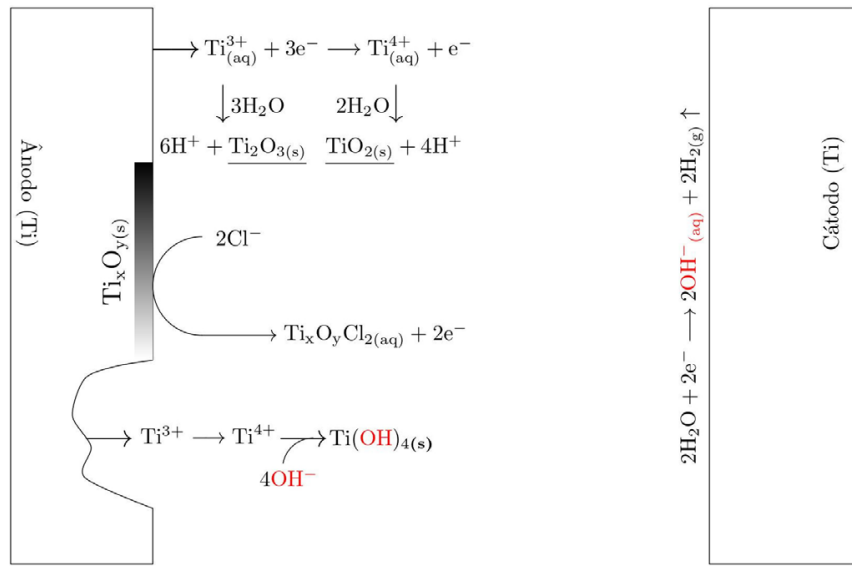

Figura 4. Esquema do sistema de eletrocoagulação com eletrodos de titânio mostrando a reação catódica, reações anódicas (formação de íons $\mathrm{Ti}^{3+} e \mathrm{Ti}^{4+}$ ), formação de filmes de óxidos de Ti(III) e Ti(IV) e a dissolução dos filmes na presença de ânions de cloro

O efeito da adição de haletos à solução como alternativa para melhorar a eletrofloculação sobre eletrodos de Ti também foi investigado. ${ }^{150,151} \mathrm{Na}$ presença de íons $\mathrm{Br}^{-}$por exemplo, o potencial de corrosão de Ti é de aproximadamente $1,4 \mathrm{~V} v s . \mathrm{Ag} / \mathrm{AgCl} .{ }^{152} \mathrm{E}$ a reação dos óxidos $\left(\mathrm{Ti}_{2} \mathrm{O}_{3}\right.$ e $\left.\mathrm{TiO}_{2}\right)$ de titânio com íons haletos formam espécies mais solúveis que, ao serem solubilizadas, deixarão exposta a superfície do metal.

Uma grande vantagem do uso do titânio em processos de eletrofloculação é a produção de um agente coagulante não tóxico que apresenta as características essenciais para desestabilizar emulsões no processo de eletrocoagulação, como destacado por Al-Ghafri et al. ${ }^{153}$ além do próprio titânio ser um metal não tóxico e relativamente barato.

\section{Zinco}

Uma vez em solução, os íons $\mathrm{Zn}^{2+}$ gerados pela eletrodissolução do ânodo de zinco (Equação 41) em processos de eletrofloculação, darão origem ao seu hidróxido correspondente, seja pela reação com íons hidroxila em meio alcalino (Equação 42), seja pela reação com água em meio ácido (Equação 43), o qual agirá como agente coagulante no sistema.

$$
\mathrm{Zn}_{(\mathrm{s})} \rightarrow \mathrm{Zn}_{(\mathrm{aq})}^{2+}+2 \mathrm{e}^{-}
$$

$$
\begin{gathered}
\mathrm{Zn}_{(\text {aq })}^{2+}+2 \mathrm{OH}_{(\mathrm{aq})}^{-} \rightarrow \mathrm{Zn}(\mathrm{OH})_{2(\mathrm{~s})} \\
\mathrm{Zn}_{(\mathrm{aq})}^{2+}+2 \mathrm{H}_{2} \mathrm{O}_{(\mathrm{l})} \rightarrow \mathrm{Zn}(\mathrm{OH})_{2(\mathrm{~s})}+2 \mathrm{H}_{(\mathrm{aq})}^{+}
\end{gathered}
$$

Hussin et al. ${ }^{154}$ tem demonstrado que a utilização de ânodo de zinco pode ser aplicado com sucesso na remoção de chumbo (II) em águas residuárias. O processo apresentou eficiência de 99,9\% em 10 minutos de tratamento, sob densidade de corrente igual a $1,13 \mathrm{~mA} \mathrm{~cm}^{-2}$. Zinco também foi utilizado como ânodo de sacrifício por Mohd et al. ${ }^{155}$ no estudo de remediação de uma solução aquosa contendo arsenito. A forte adsorção do arsenito no eletrodo na faixa de pH entre 2 e 7, e conversão do arsenito em arsenato (Equação 44), favorece a formação preferencial de $\mathrm{H}_{2} \mathrm{AsO}^{-}$. Na sequência, há a formação de um complexo insolúvel entre o arsenato e o hidróxido de zinco gerado in situ (Equação 45) favorecendo a remoção de $99,89 \%$ de arsenito no processo. Para isto, as melhores condições de tratamento foram obtidas para concentração inicial de arsenito $2,0 \mathrm{mg} \mathrm{L}^{-1}$; $\mathrm{pH}=6,0$; potencial aplicado $30 \mathrm{~V}$; tempo de reação 16 minutos e temperatura de $30^{\circ} \mathrm{C}$.

$$
\begin{gathered}
\mathrm{AsO}_{2(\mathrm{aq})}^{-}+2 \mathrm{OH}_{(\mathrm{aq})}^{-} \rightarrow \mathrm{H}_{2} \mathrm{AsO}_{4(\mathrm{aq})}^{-}+2 \mathrm{e}^{-} \\
\mathrm{Zn}(\mathrm{OH})_{2(\mathrm{~s})}+\mathrm{H}_{2} \mathrm{AsO}_{4(\mathrm{aq})}^{-} \rightarrow \mathrm{ZnHAsO}_{4(\mathrm{~s})}+\mathrm{H}_{2} \mathrm{O}_{(\mathrm{l})}+\mathrm{OH}_{(\mathrm{aq})}^{-}
\end{gathered}
$$

O trabalho proposto por Fajardo et al. ${ }^{118}$ tem demonstrado que o uso de zinco como ânodo e cátodo de aço inoxidável em eletrocoagulação é eficaz para remoção de $84,2 \%$ de compostos fenólicos e redução de $40,3 \%$ de demanda química de oxigênio em águas residuárias. Com o uso dos mesmos materiais do cátodo e ânodo, Safwat et al. ${ }^{130}$ têm demonstrado a possibilidade de reduzir $66 \%$ de ureia em um rejeito sintético, entretanto os pesquisadores observaram que a técnica, quando aplicada no tratamento de amostras reais, apresenta menor eficiência na remoção de ureia, apesar de ser efetiva na remoção de outros compostos poluentes. $\mathrm{O}$ trabalho de Aoudj et al. ${ }^{27}$ traz excelentes resultados para a remoção de dodecil sulfato de sódio, fluoreto e amônia em rejeitos de indústria têxtil pela combinação de eletrocoagulação EC-EF, que também se mostra promissora para a remoção de nitratos em matriz aquosa. Nesse mesmo trabalho, foi verificada uma remoção de $96 \%$ para nitratos quando aplicado uma densidade de corrente em torno de $3,2 \mathrm{~mA} \mathrm{~cm}^{-2}$ dentro de 30 minutos.

\section{ACOPLAMENTO DE ELETROFLOCULAÇÃO E OUTROS MÉTODOS DE TRATAMENTO}

O acoplamento da técnica de eletrofloculação para a remoção prévia de contaminantes brutos em águas residuárias (óleos, graxas e sólidos suspensos) em etapa anterior ou posterior a outros métodos de tratamento, tem sido bastante discutido na literatura. $\mathrm{O}$ trabalho executado por Chanikya et al. ${ }^{156}$ traz um exemplo relevante a respeito da junção de técnicas eletroquímicas para o tratamento de efluentes têxteis. No estudo realizado, a combinação do processo de oxidação eletroquímica avançada (POEA) com a eletrocoagulação (EC) utilizando placas de platina/titânio e ferro como ânodo e cátodo respectivamente em ambos os processos, foi verificado um relevante sinergismo entre as técnicas, promovendo uma diminuição de $93 \%$ da demanda química de oxigênio do efluente proveniente da indústria de corantes, com um menor consumo específico de energia e menor geração de lodo. Uma grande quantidade de estudos tem apontado que a eletrocoagulação é um tratamento eficiente para águas residuais de indústria com um nível significativo de poluição como método preliminar. $^{27-32}$ Mas pode atingir níveis de remoção muito mais adequados, quando combinado a outros processos de tratamento. Por exemplo, o acoplamento do processo EC com processos biológicos, 
Tabela 4. Principais acoplamentos de técnicas encontrados na literatura

\begin{tabular}{|c|c|c|c|c|}
\hline Tipo de Acoplamento & Matriz estudada & Eletrodos empregados & $\begin{array}{l}\text { Porcentagem de } \\
\text { remoção }\end{array}$ & Referência \\
\hline Oxidação eletroquímica + eletrocoagulação & Rejeitos da indústria têxtil & Platina/titânio & $93 \%$ & 156 \\
\hline Eletrocoagulação + biofiltração & $\begin{array}{l}\text { Material proveniente do aterro } \\
\text { sanitário }\end{array}$ & Alumínio/aço & $82 \%$ & 35 \\
\hline Eletrocoagulação + eletro-oxidação & Mistura de nitratos e fosfatos & Diamante dopado com boro & $\begin{array}{l}88 \% \\
97 \%\end{array}$ & 159 \\
\hline Eletroagulação + ozonição & $\begin{array}{l}\text { Efluentes da indústria } \\
\text { siderúrgica }\end{array}$ & Aço & $\begin{array}{c}99,8 \%, \\
94,7 \%, \\
95 \% \\
46,5 \%\end{array}$ & 34 \\
\hline Eletrocoagulação + fotocatálise & Águas contaminadas & Titânio & $91 \%$ & 33 \\
\hline
\end{tabular}

químicos ou processos de oxidação avançada pode promover a obtenção de uma água muito mais pura e melhor conformidade com as normas ambientais.

O acoplamento de EC com a biofiltração tem sido proposto por Dia et al., ${ }^{35}$ para tratamento de materiais lixiviados de aterro sanitário. De acordo com os autores, o tratamento apresentou alta eficiência para diminuição da demanda química de oxigênio, fósforo, metais, amônia e demanda bioquímica de oxigênio. Vários outros estudos têm explorado a combinação entre eletrocoagulação e eletrooxidação..$^{27-29,31,32,157,158} \mathrm{O}$ resultado do tratamento combinado mostrouse muito satisfatórios para águas residuais da indústria de curtumes e agroalimentares, além da redução do consumo de energia usualmente gerado em um tratamento utilizando-se apenas eletro-oxidação.

A influência dos principais parâmetros operacionais em eletrodos de aço para a remoção simultânea de nitratos e fosfatos em matrizes complexas assim como o melhoramento da eficiência do processo EC por meio do acoplamento com métodos eletroquímicos foi também estudada por Ghazouani et al. ${ }^{159}$ Tal combinação resultou na oxidação da amônia gerada, melhorando consideravelmente a qualidade das águas residuais tratadas. Em adição, o método combinado ofereceu um consumo de energia por unidade de poluente de $0,99 \mathrm{~kW} \mathrm{~h} \mathrm{~kg}^{-1} \mathrm{~N}^{-1}$, e mudança de cinética de remoção para os fosfatos, nitratos e outros compostos nitrogenados.

O acoplamento da técnica de eletrofloculação com ozonização também se mostrou bastante eficiente para a remoção de cianeto e cloreto em efluentes da indústria siderúrgica. ${ }^{34} \mathrm{~A}$ integração das técnicas forneceu um resultado altamente satisfatório, configurando uma remoção de $99,8 \%, 94,7 \%, 95 \%$ e $46,5 \%$ para íons cianeto, cloreto e para a demanda química de oxigênio (DQO) e demanda bioquímica de oxigênio (DBO), respectivamente.

A literatura também reporta a associação de eletrofloculação com fotocatálise. Para isso, Boroski et al. ${ }^{33}$ demonstram que titânio pode ser um ânodo promissor, quando o lodo gerado é seco, calcinado e usado em fotocatálise. Isso é, o material gerado como resíduo na eletrofloculação pode ser relevante na fabricação de nanopartículas de dióxido de titânio $\left(\mathrm{TiO}_{2}\right)$, a serem usados como semicondutor fotoativo. De acordo com os autores, esse material, quando submetido a irradiação UV, age como catalisador na degradação de poluentes em águas contaminadas, gerando um eficiente processo fotocatalítico.

A eletrocoagulação sobre eletrodos de Fe associada ao tratamento fotocatalítico usando $\mathrm{TiO}_{2}$ também foi aplicada em efluentes farmacêuticos, industriais e cosméticos, os quais são descritos na literatura. ${ }^{33}$ A subsequente fotocatálise após a eletrocoagulação reduziu drasticamente os contaminantes refratários do efluente.

A análise da Tabela 4 permite verificar que é possível realizar o acoplamento de técnicas juntamente com a eletrocoagulação e sobretudo verifica-se um acoplamento com técnicas eletroquímicas, envolvendo processos oxidativos avançados. Dentre as técnicas empregadas, a fotoeletrocatálise entra como uma técnica que abre bastante perspectivas no quesito acoplamento de técnicas.

Esses resultados demonstram que o acoplamento da eletrocoagulação com outros processos de tratamento pode ser uma configuração bem conveniente para o tratamento de matrizes complexas, o que reitera ainda mais a versatilidade e potencialidade da eletrocoagulação como técnica de tratamento para rejeitos.

\section{PERSPECTIVAS FUTURAS}

A eletrocoagulação é uma técnica conhecida e bastante estudada pelo meio acadêmico. Há na literatura uma grande quantidade de estudos envolvendo a aplicação dessa técnica para o tratamento de água, sendo que muitos desses estudos têm como objetivo encontrar, experimentalmente e/ou estatisticamente, as melhores condições de trabalho para tratar um determinado efluente com um arranjo específico de eletrodos, como pode ser observado pelas Tabelas 1 a 3. Contudo, há certa escassez na literatura de trabalhos que buscam estudar e elucidar, de maneira sistemática, as regras que regem o projeto de reatores para a eletrocoagulação. ${ }^{160}$ Isso ocorre por causa da complexidade das interações envolvidas no processo e, consequentemente, da falta de conhecimento sobre essas interações, o que dificulta a implementação dessa tecnologia em escala industrial. ${ }^{161}$ Para que a técnica possa ser amplamente utilizada em grandes escalas, é preciso que haja pesquisas que mostrem, de maneira aprofundada, as complexas interações que ocorrem no sistema, bem como proponham modelos matemáticos mais completos, que tornarão possível a construção de reatores mais eficientes e econômicos.

Ademais, pode-se destacar a importância do desenvolvimento de novas estratégias para minimizar a formação de camadas passivantes nos eletrodos, que diminuem a eficiência do tratamento, ${ }^{162}$ principalmente estratégias que não necessitam da adição de produtos químicos ao sistema, de forma a evitar poluição secundária. Uma estratégia interessante que vem sendo adotada é a aplicação de corrente alternada no processo, a qual retarda a passivação do cátodo e diminuí a deterioração do ânodo. ${ }^{162,163}$ Dessa forma, é essencial a busca por diferentes formas de evitar o rápido desgaste dos eletrodos, tornando o processo mais econômico, ao mesmo tempo que a eficiência é aumentada.

O estudo de eletrodos não convencionais, que já foi amplamente discutido ao longo deste trabalho, é de suma importância para o desenvolvimento de tratamentos de diversas matrizes sem os problemas associados aos eletrodos convencionais. ${ }^{15}$ Nesse sentido, pode-se destacar a importância de estudos voltados ao acoplamento da eletrocoagulação com outras técnicas de tratamento e desinfecção de água. ${ }^{33,34,164}$ 


\section{AGRADECIMENTOS}

Os autores agradecem ao suporte financeiro do INCTDATREM (Instituto Nacional para Tecnologias Alternativas para Detecção, Avaliação Toxicológica de Micropoluentes e Radioativos (FAPESP: 2014/50945-4, CNPq: 465571/2014-0 e CAPES:88887.136426/2017-00), e à Fundação de Amparo à Pesquisa do Estado de São Paulo (FAPESP), processo no 2020/02877-0, pelo financiamento do projeto de pesquisa.

\section{REFERÊNCIAS}

1. Harif, T.; Khai, M.; Adin, A.; Water Res. 2012, 46, 3177.

2. Moreno, H. A. C.; Cocke, D. L.; Gromes, J. A.; Morkovsky, P.; Parga, J. R.; Peterson, E.; Garcia, C.; Ind. Eng. Chem. Res. 2009, 48, 2275.

3. Chen, G.; Sep. Purif. Technol. 2004, 38, 11.

4. Matteson, M. J.; Dobson, R. L.; Glenn, R. W.; Kukunoor, N. S.; Waits, W. H.; Clayfield, E. J.; Colloids Surf., A 1995, 104, 101.

5. Naje, A. S.; Chelliapan, S.; Zakaria, Z.; Ajeel, M. A.; Alaba, P. A.; Rev. Chem. Eng. 2017, 33, 263.

6. Barrera-Díaz, C. E.; Balderas-Hernández, P.; Bilyeu, B.; In Electrochemical Water and Wastewater Treatment; Martínez-Huitle, C. A., Rodrigo, M. A., Scialdone, O., eds.; Butterworth-Heinemann, 2018; p. 61.

7. Ukiwe, L. N.; Okolue, B. N.; Ikechukwu, I.; Chidi, D.; Gerald, O.; Nweze, C. A.; J. Adv. Chem. 2013, 9, 1988.

8. de Aquino Neto, S.; Magri, T. C.; da Silva, G. M.; de Andrade, A. R.; Quim. Nova 2011, 34, 1468.

9. Mohammed, T. J.; Shakir, E.; Egypt. J. Pet. 2017, 27, 31.

10. http://www.planalto.gov.br/ccivil_03/_ato2007-2010/2010/lei/112305. htm, acessada em novembro 2021.

11. Santos, G. de O. S.; Pupo, M. M. de S.; Vasconcelos, V. M.; Eguiluz, K. I. B.; Banda, G. R. S. In Electrochemical Water and Wastewater Treatment; Martínez-Huitle, C. A., Scialdone, O., Rodrigo, M. A., eds.; Butterworth-Heinemann: Oxford, 2018; p. 77.

12. Kyzas, G. Z.; Matis, K. A.; J. Mol. Liq. 2016, 220, 657.

13. Paschoal, F. M. M.; Tremiliosi-Filho, G.; Quim. Nova 2005, 28, 766.

14. Garcia-Segura, S.; Eiband, M. M. S. G.; Melo, J. V. de; Martínez-Huitle, C. A.; J. Electroanal. Chem. 2017, 801, 267.

15. Mollah, M. Y. A.; Schennach, R.; Parga, J. R.; Cocke, D. L.; J. Hazard. Mater. 2001, 84, 29.

16. Jarvis, P.; Jefferson, B.; Parsons, S. A.; Water Supply 2018, 4, 79.

17. Taylor, P.; Matis, K. A.; Peleka, E. N.; Sep. Sci. Technol. 2010, 45, 2465.

18. Adhoum, N.; Monser, L.; Chem. Eng. Process. Process Intensif. 2004, 43, 1281.

19. Gadd, A. S.; Ryan, D. R.; Kavanagh, J. M.; Barton, G. W.; Water Sci. Technol. 2010, 61, 3221.

20. Tchamango, S.; Nanseu-njiki, C. P.; Ngameni, E.; Hadjiev, D.; Darchen, A.; Sci. Total Environ. 2010, 408, 947.

21. Bouhezila, F.; Hariti, M.; Lounici, H.; Mameri, N.; Desalination 2011, $280,347$.

22. Zaied, M.; Bellakhal, N.; J. Hazard. Mater. 2009, 163, 995.

23. World Health Organization; Guidelines for Drinking-Water Quality: Fourth Edition Incorporating the First Addendum, Geneva, 2014, p. 219.

24. Sasson, M. B.; Adin, A.; Water Res. 2010, 44, 3973.

25. Cheng, W. P.; Chi, F. H.; Water Res. 2002, 36, 4583.

26. Chen, X.; Chen, G.; Yue, P. L.; Environ. Sci. Technol. 2002, $36,778$.

27. Aoudj, S.; Khelifa, A.; Drouiche, N.; Chemosphere 2017, 180, 379.

28. Aoudj, S.; Cheknane, B.; Zemmouri, H.; Zermane, F.; Khelifa, A.; Hecini, M.; Drouiche, N.; Desalin. Water Treat. 2017, 82, 262.

29. Ghazouani, M.; Akrout, H.; Jellali, S.; Bousselmi, L.; Sci. Total Environ. 2019, 647, 1651.
30. He, Y.; Lin, H.; Dong, Y.; Li, B.; Wang, L.; Chu, S.; Luo, M.; Liu, J.; Chem. Eng. J. 2018, 347, 669.

31. Majlesi, M.; Mohseny, S. M.; Sardar, M.; Golmohammadi, S.; Sheikhmohammadi, A.; Sustain. Environ. Res. 2016, 26, 287.

32. Kuokkanen, V.; Kuokkanen, T.; Rämö, J.; Lassi, U.; Roininen, J.; J. Water Process Eng. 2015, 8, 50.

33. Boroski, M.; Rodrigues, A. C.; Garcia, J. C.; Sampaio, L. C.; Nozaki, J.; Hioka, N.; J. Hazard. Mater. 2009, 162, 448.

34. Das, P. P.; Anweshan, A.; Mondal, P.; Sinha, A.; Biswas, P.; Sarkar, S.; Purkait, M. K.; Chemosphere 2021, 263, 128370.

35. Dia, O.; Drogui, P.; Buelna, G.; Dubé, R.; Waste Manage. 2018, 75, 391.

36. Melchiors, M. S.; Piovesan, M.; Becegato, V. R.; Becegato, V. A.; Tambourgi, E. B.; Paulino, A. T.; J. Environ. Manage. 2016, 182, 574.

37. Symonds, E. M.; Cook, M. M.; Mcquaig, S. M.; Ulrich, R. M.; Schenck, R. O.; Lukasik, J. O.; Sci. Rep. 2015, 5, 9380.

38. Wang, H.; Jiang, J.; Xu, R.; Li, F.; Desalin. Water Treat. 2012, 37, 62.

39. Souza, F. L.; Cotillas, S.; Saéz, C.; Cañizares, P.; Lanza, M. R. V; Rodrigo, M. A.; J. Chem. Technol. Biotechnol. 2014, 91, 82.

40. Daneshvar, N.; Sorkhabi, H. A.; Kasiri, M. B.; J. Hazard. Mater. 2004, 112, 55.

41. Daneshvar, N.; Oladegaragoze, A.; Djafarzadeh, N.; J. Hazard. Mater. 2006, 129, 116.

42. Fleck, L.; Eyng, E.; Rev. Eixo (2013), doi: 10.19123/eixo.v2i2.107.

43. Takdastan, A.; Hashemzadeh, B.; Mohammadi, M. J.; Rahimi, S.; Arch. Hyg. Sci. 2017, 6, 66.

44. Carmona, M.; Khemis, M.; Leclerc, J. P.; Lapicque, F.; Chem. Eng. Sci. 2006, 61, 1237.

45. Priya, M.; Jeyanthi, J.; Microchem. J. 2019, 150, 104070.

46. Moussa, D. T.; El-naas, M. H.; Nasser, M.; Al-marri, M. J.; J. Environ. Manage. 2017, 186, 24.

47. Nguyen, T. T. N.; Lee, M. S.; Geosystem Eng. 2019, 22, 232.

48. Sarpola, A.; Tese de Doutorado, Universidade de Oulu, Finlândia, 2007.

49. Bi, S.; Wang, C.; Cao, Q.; Zhang, C.; Coord. Chem. Rev. 2004, 248, 441.

50. Bazrafshan, E.; Moein, H.; Mostafapour, F. K.; Nakhaie, S.; J. Chem. 2013, 2013, 7.

51. Bukhari, A. A.; Bioresour. Technol. 2008, 99, 914.

52. Tang, X.; Zheng, H.; Teng, H.; Sun, Y.; Guo, J.; Xie, W.; Yang, Q.; Chen, W.; Desalin. Water Treat. 2016, 57, 1733.

53. Shahedi, A.; Darban, A. K.; Taghipour, F.; Jamshidi-Zanjani, A.; Curr. Opin. Electrochem. 2020, 22, 154.

54. Mansouri, K.; Ibrik, K.; Bensalah, N.; Abdel-Wahab, A.; Ind. Eng. Chem. Res. 2011, 50, 13362.

55. Dura, A.; Breslin, C. B.; J. Hazard. Mater. 2019, 366, 39.

56. Noubactep, C.; Schöner, A.; J. Hazard. Mater. 2010, 175, 1075.

57. Hu, C. Y.; Lo, S. L.; Kuan, W. H.; Water Res. 2003, 37, 4513.

58. Murugananthan, M.; Raju, G. B.; Prabhakar, S.; J. Hazard. Mater. 2004, 109, 37.

59. Davis, C. C.; Chen, H. W.; Edwards, M.; Environ. Sci. Technol. 2002, $36,582$.

60. Duan, J.; Gregory, J.; Adv. Colloid Interface Sci. 2003, 100, 475.

61. Kallay, N.; Kovačević, D.; Salac, S.; In Surface Complexation Modelling; Lützenkirchen, J., ed.; Academic Press: Cambridge, 2006; p. 133.

62. Hayes, K.; Redden, G.; Ela, W.; Leckie, J.; J. Colloid Interface Sci. 1991, 142, 448.

63. Jin, P.; Song, J.; Wang, X. C.; Jin, X.; J. Environ. Sci. 2017, 64, 181.

64. Emamjomeh, M. M.; Sivakumar, M.; Varyani, A. S.; Desalination 2011, $275,102$.

65. Heidmann, I.; Calmano, W.; Sep. Purif. Technol. 2008, 61, 15.

66. Siegel, M.; Bryan, C. In Environmental Geochemistry; Holland, H. D., Turekian, K. K., eds.; Elsevier Science: Amsterdam, 2014; Vol. 11, p. 191.

67. Vepsäläinen, M.; Sillanpää, M. In Advanced Water Treatment 
Electrochemical Methods; Sillanpää, M., ed.; Elsevier: Amsterdam, 2020; p. 1.

68. Tadros, T.; Encyclopedia of Colloid and Interface Science; Tadros, T., ed.; $1^{\text {st }}$ ed., Springer-Verlag: Berlim, 2013.

69. Gumustas, M.; Sengel-Turk, C. T.; Gumustas, A.; Ozkan, S. A.; Uslu, B.; In Multifunctional Systems for Combined Delivery, Biosensing and Diagnostics; Grumezescu, A., ed.; Elsevier: Amsterdam, 2017; p. 67.

70. Adair, J. H.; Suvaci, E.; Sindel, J.; In Encyclopedia of Materials: Science and Technology; Buschow, K. H. J., Cahn, R. W., Flemings, M. C., Ilschner, B., Kramer, E. J., Mahajan, S., Veyssière, P., eds.; Elsevier: Amsterdam, 2001; p. 1.

71. Creux, P.; Lachaise, J.; Graciaa, A.; Beattie, J. K.; Djerdjev, A. M.; J. Phys. Chem. B 2009, 113, 14146

72. Marinova, K. G.; Alargova, R. G.; Denkov, N. D.; Velev, O. D.; Petsev, D. N.; Ivanov, I. B.; Borwankar, R. P.; Langmuir 1996, 12, 2045.

73. Ghernaout, D.; Naceur, M. W.; Ghernaout, B.; Desalin. Water Treat. 2011, 28, 287.

74. Pal, P. In Groundwater Arsenic Remediation; Pal, P., ed.; ButterworthHeinemann: Oxford, 2015; p. 25.

75. Chang, Q.; In Colloid and Interface Chemistry for Water Quality Control; Chang, Q., ed.; Academic Press: Lanzhou, 2016; p. 79.

76. Horinek, D. In Encyclopedia of Applied Electrochemistry; Kreysa, G., Ota, K., Savinell, R. F., eds.; Springer: New York, 2014; p. 343.

77. Shammas, N. K. In Physicochemical Treatment Processes; Wang, L. K., Hung, Y. T., Shammas, N. K., eds.; Humana Press: Totowa, 2005; p. 103.

78. Solak, M.; Kiliç, M.; Hüseyin, Y.; Şencan, A.; J. Hazard. Mater. 2009, 172, 345 .

79. Bashir, M. J. K.; Han, T. M.; Wei, L. J.; Aun, N. C.; Amr, S. S. A.; Water Sci. Technol. 2016, 73, 2704.

80. Hakizimana, J. N.; Gourich, B.; Vial, C.; Drogui, P.; Oumani, A.; Naja, J.; Hilali, L.; Desalination 2016, 393, 90.

81. Mbacké, M. K.; Kane, C.; Diallo, N. O.; Diop, C. M.; Chauvet, F.; Comtat, M.; Tzedakis, T.; J. Environ. Chem. Eng. 2016, 4, 4001.

82. Verma, A. K.; J. Water Process Eng. 2017, 20, 168.

83. Franco, D.; Lee, J.; Arbelaez, S.; Cohen, N.; Kim, J. Y.; Ecol. Eng. 2017, 108, 589 .

84. Doggaz, A.; Attour, A.; Mostefa, M. L. P.; Tlili, M.; Lapicque, F.; Sep. Purif. Technol. 2018, 203, 217.

85. Ammar, S. H.; Akbar, A. S.; Chin. J. Chem. Eng. 2018, 26, 879.

86. Nariyan, E.; Sillanpää, M.; Wolkersdorfer, C.; Sep. Purif. Technol. 2018, 193, 386.

87. Danial, R.; Sobri, S.; Abdullah, L. C.; Mobarekeh, M. N.; Chemosphere 2019, 233, 559.

88. Hansen, H. K.; Peña, S. F.; Gutiérrez, C.; Lazo, A.; Lazo, P.; Ottosen, L. M.; J. Hazard. Mater. 2019, 364, 78.

89. Zhang, X.; Lu, M.; Idrus, M. A. M.; Crombie, C.; Jegatheesan, V.; Process Saf. Environ. Prot. 2019, 126, 18.

90. Díaz, C. E. B.; González-Rivas, N.; J. Chem. 2015, 2015, 1.

91. Brito, J. F.; Ferreira, L. de O.; Silva, J. P.; Ramalho, T. C.; Quim. Nova 2012, 35, 728

92. Wu, M.; Hu, Y.; Liu, R.; Lin, S.; Sun, W.; Lu, H.; Sci. Total Environ. 2019, 696, 134063

93. Kumari, S.; Kumar, R. N.; Chemosphere 2020, 273, 128571.

94. Amarine, M.; Lekhlif, B.; Sinan, M.; El-Rharras, A.; Echaabi, J.; Groundw. Sustain. Dev. 2020, 11, 100371.

95. Joao, J. J.; Emerick, T.; Filho, U. de S.; Nishihora, R. K.; Quim. Nova 2017, 41, 163

96. Meneses, J. M. de; Vasconcelos, R. de F.; Fernandes, T. de F.; de Araújo, G. T.; Quim.Nova 2012, 35, 235 .

97. Kilany, A. Y.; Nosier, S. A.; Hussein, M.; Abdel-Aziz, M. H.; Sedahmed, G. H.; Sep. Purif. Technol. 2020, 248, 117056.

98. Crespilho, F. N.; Santana, C. G.; Rezende, M. O. O.; Quim. Nova 2004, $27,387$.
99. Parmentier, D.; Manhaeghe, D.; Baccini, L.; Meirhaeghe, R. V.; Rousseau, D. P. L.; Hulle, S. V.; Algal Res. 2020, 47, 101828.

100. Kumar, P. R.; Chaudhari, S.; Khilar, K. C.; Mahajan, S. P.; Chemosphere 2004, 55, 1245 .

101. Şengil, I. A.; Özacar, M.; J. Hazard. Mater. 2006, 137, 1197.

102. Vasudevan, S.; Lakshmi, J.; Jayaraj, J.; Sozhan, G.; J. Hazard. Mater. 2009, 164, 1480

103. Vasudevan, S.; Lakshmi, J.; Sozhan, G.; Clean - Soil, Air, Water 2009, $37,45$.

104. Vasudevan, S.; Lakshmi, J.; Sozhan, G.; Clean - Soil, Air, Water 2009, 37,372 .

105. Kabdaşli, I.; Keleş, A.; Ölmez-Hanci, T.; Tünay, O.; Arslan-Alaton, I.; J. Hazard. Mater. 2009, 171, 932.

106. Vasudevan, S.; Sheela, S. M.; Lakshmi, J.; Sozhan, G.; J. Chem. Technol. Biotechnol. 2010, 85, 926.

107. Vasudevan, S.; Lakshmi, J.; Sep. Purif. Technol. 2011, 80, 643.

108. Vasudevan, S.; Lakshmi, J.; Sozhan, G.; J. Hazard. Mater. 2011, 192, 26.

109. Vasudevan, S.; Lakshmi, J.; Sozhan, G.; Desalination 2011, 275, 260.

110. Murthy, Z. V. P.; Parmar, S.; Desalination 2011, 282, 63.

111. Wei, M. C.; Wang, K. S.; Huang, C. L.; Chiang, C. W.; Chang, T. J.; Lee, S. S.; Chang, S. H.; Chem. Eng. J. 2012, 192, 37.

112. Ali, I.; Asim, M.; Khan, T. A.; Int. J. Environ. Sci. Technol. 2013, 10, 377.

113. Ganesan, P.; Lakshmi, J.; Sozhan, G.; Vasudevan, S.; Can. J. Chem. Eng. 2013, 91, 448.

114. Vasudevan, S.; Lakshmi, J.; Sozhan, G.; Desalination 2013, 310, 122

115. Kruk, D. J.; Elektorowicz, M.; Oleszkiewicz, J. A.; Chemosphere 2014, $101,28$.

116. Mansoorian, H. J.; Mahvi, A. H.; Jafari, A. J.; Sep. Purif. Technol. 2014, $135,165$.

117. Kamaraj, R.; Vasudevan, S.; Chem. Eng. Res. Des. 2015, 93, 522.

118. Fajardo, A. S.; Rodrigues, R. F.; Martins, R. C.; Castro, L. M.; QuintaFerreira, R. M.; Chem. Eng. J. 2015, 275, 331.

119. Barrera-Diáz, C. E.; Frontana-Uribe, B. A.; Roa-Morales, G.; Bilyeu, B.; J. Environ. Sci. Heal. - Part A Toxic/Hazardous Subst. Environ. Eng. 2015, 50, 406.

120. García-García, A.; Martínez-Miranda, V.; Martínez-Cienfuegos, I. G.; Almazán-Sánchez, P. T.; Castañeda-Juárez, M.; Linares-Hernández, I.; Fuel 2015, 149, 46

121. Prajapati, A. K.; Chaudhari, P. K.; Pal, D.; Chandrakar, A.; Choudhary, R.; J. Water Process Eng. 2016, 11, 1.

122. Linares-Hernández, I.; Barrera-Díaz, C.; Cerecero, M. V.; AlmazánSánchez, P. T.; Castañeda-Juárez, M.; Lugo, V. L.; Environ. Technol. (United Kingdom) 2017, 38, 433.

123. Widhiastuti, F.; Lin, J. Y.; Shih, Y. J.; Huang, Y. H.; Chem. Eng. J. 2018, $350,893$.

124. Devlin, T. R.; Kowalski, M. S.; Pagaduan, E.; Zhang, X.; Wei, V.; Oleszkiewicz, J. A.; J. Hazard. Mater. 2019, 368, 862

125. Safwat, S. M.; Hamed, A.; Rozaik, E.; Sep. Sci. Technol. 2019, 54, 183.

126. Dura, A.; Breslin, C. B.; J. Hazard. Mater. 2019, 374, 152

127. Isik, Z.; Arikan, E. B.; Ozay, Y.; Bouras, H. D.; Dizge, N.; Chemosphere 2020, 244, 125383

128. Safwat, S. M.; J. Water Process Eng. 2020, 34, 101137.

129. El-Ghenymy, A.; Alsheyab, M.; Khodary, A.; Sirés, I.; Abdel-Wahab, A.; Chemosphere 2020, 246, 125674.

130. Safwat, S. M.; Matta, M. E.; Sep. Sci. Technol. 2020, 55, 2500.

131. Wang, Z.; Shen, Q.; Xue, J.; Guan, R.; Li, Q.; Liu, X.; Jia, H.; Wu, Y.; Chem. Eng. J. 2020, 402, 126151.

132. Sadik, M. A.; Adv. Chem. Eng. Sci. 2019, 09, 109.

133. Chen, X.; Chen, G.; Yue, P. L.; Sep. Purif. Technol. 2000, 19, 65.

134. Bouhezila, F.; Hariti, M.; Lounici, H.; Mameri, N.; Desalination 2011 , $280,347$. 
135. Mahmad, M. K. N.; Rozainy, M. A. Z. M. R.; Abustan, I.; Baharun, N.; Procedia Chem. 2016, 19, 681.

136. Nariyan, E.; Sillanpää, M.; Wolkersdorfer, C.; Sep. Purif. Technol. 2017, $177,363$.

137. Breslin, C. B.; Friery, L. P.; Carroll, W. M.; Corros. Sci. 1994, 36, 85.

138. Breslin, C. B.; Friery, L. P.; Corros. Sci. 1994, 36, 239.

139. Barrera-Díaz, C.; Frontana-Uribe, B.; Bilyeu, B.; Chemosphere 2014, 105, 160.

140. Cudennec, Y.; Lecerf, A.; Solid State Sci. 2003, 5, 1471.

141. Weisbart, C.; Raghavan, S.; Muralidharan, K.; Potter, B. G.; J. Water Process Eng. 2020, 36, 101249.

142. Yruela, I.; Brazilian J. Plant Physiol. 2005, 17, 145.

143. Ellingsen, D. G.; Møller, L. B.; Aaseth, J. In Handbook on the Toxicology of Metals: Fourth Edition; Nordberg, G. F., Fowler, B. A., Nordberg, M., eds.; Academic Press: Cambridge, 2015; p. 765.

144. Vik, E. A.; Carlson, D. A.; Eikum, A. S.; Gjessing, E. T.; Water Res. 1984, 18, 1355.

145. Kim, J. H.; An, B. M.; Lim, D. H.; Park, J. Y.; Water Res. 2018, 132, 200.

146. Hug, A.; Udert, K. M.; Water Res. 2013, 47, 289.

147. Bessegato, G. G.; Guaraldo, T. T.; Brito, J. F.; Brugnera, M. F.; Zanoni, M. V. B.; Electrocatalysis 2015, 6, 415.

148. Chen, C.; Chen, J.; Chao, C.; Say, W. C.; J. Mater. Sci. 2005, 40, 4053.

149. Shon, H. K.; Phuntsho, S.; Vigneswaran, S.; Kandasamy, J.; Nghiem, L. D.; Kim, G. J.; Kim, J. B.; Kim, J. H.; Environ. Sci. Technol. 2010, 44, 5553 .
150. Escrivà-Cerdán, C.; Blasco-Tamarit, E.; García-García, D. M.; GarcíaAntón, J.; Akid, R.; Walton, J.; Electrochim. Acta 2013, 111, 552.

151. Liu, C.; Leyland, A.; Bi, Q.; Matthews, A.; Surf. Coatings Technol. 2001, $141,164$.

152. Basame, S. B.; White, H. S.; J. Electrochem. Soc. 2000, 147, 1376.

153. Al-Ghafri, B.; Lau, W. J.; Al-Abri, M.; Goh, P. S.; Ismail, A. F.; J. Water Process Eng. 2019, 32, 100970.

154. Hussin, F.; Abnisa, F.; Issabayeva, G.; J. Clean. Prod. 2017, 147, 206.

155. Mohd, I. A.; Khan, A. T. A.; Int. J. Environ. Sci. Technol. 2012, 10, 377.

156. Chanikya, P.; Nidheesh, P. V.; Babu, D. S.; Gopinath, A.; Kumar, M. S.; Sep. Purif. Technol. 2021, 254, 117570.

157. Azarian, G.; Miri, M.; Nematollahi, D.; Environ. Prog. Sustain. Energy 2018, 37, 637 .

158. Hashim, K. S.; Al-Khaddar, R.; Jasim, N.; Shaw, A.; Phipps, D.; Kot, P.; Pedrola, M. O.; Alattabi, A. W.; Abdulredha, M.; Alawsh, R.; Sep. Purif. Technol. 2019, 210, 135.

159. Ghazouani, M.; Bousselmi, L.; Akrout, H.; J. Environ. Chem. Eng. 2020, $8,104509$.

160. Holt, P. K.; Barton, G. W.; Mitchell, C. A.; Chemosphere 2007, 59, 355.

161. Nepo, J.; Gourich, B.; Cha, M.; Stiriba, Y.; Vial, C.; Drogui, P.; Naja, J.; Desalination 2017, 404, 1.

162. Cerqueira, A. A.; Souza, P. S. A.; Marques, M. R. C.; Braz. J. Chem. Eng. 2014, 31, 693.

163. Eyvaz, M.; Kirlaroglu, M.; Aktas, T. S.; Yuksel, E.; Chem. Eng. J. 2009, $153,16$.

164. Ghernaout, D.; EC Microbiology 2019, 15, 79. 